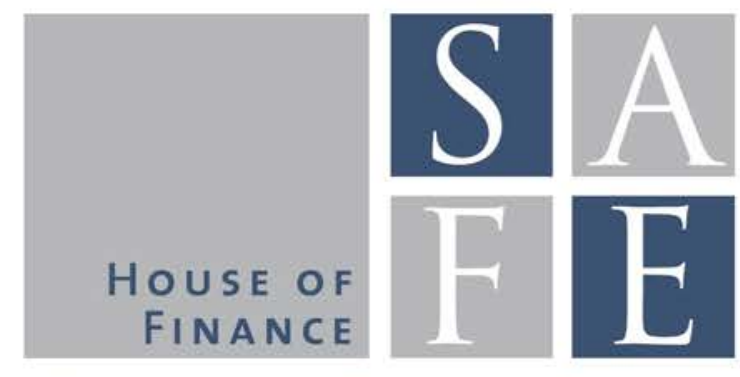

WORKING PAPER SERIES

Patrick Grüning

\title{
Heterogeneity in the Internationalization of R\&D: Implications for Anomalies in Finance and Macroeconomics
}

SAFE Working Paper No. 185

SAFE I Sustainable Architecture for Finance in Europe A cooperation of the Center for Financial Studies and Goethe University Frankfurt 


\section{Non-Technical Summary}

Technology spillovers are important drivers of economic growth. However, in the theoretical spillover literature typically only new firms undertake innovations, yielding endogenous economic growth. In this paper, I do not restrict the model to feature only homogeneous innovations. Instead, I analyze the equilibrium implications of technology spillovers within an endogenous growth Schumpeterian model with heterogeneous innovations by incumbents (current monopolists) and entrants (new firms).

The model in this article is similar to the one used by Grüning (2017). The only difference is the presence of heterogeneous instead of homogeneous innovations. Small incremental innovations are undertaken by incumbents allowing them to increase their monopoly profits. Entrants undertake large radical innovations and displace incumbents upon a successful innovation giving rise to "Creative Destruction" effects (Schumpeter, 1934, 1942). Technology spillovers are modeled following Grüning (2017), i.e. both types of innovating firms need to use both countries' final goods to undertake R\&D.

In particular, different home bias parameters for the Cobb-Douglas R\&D expenditure bundles of incumbents and entrants are used, allowing heterogeneity in the internationalization of R\&D efforts. In the benchmark heterogeneous spillover calibration, the home bias parameter in incumbents' R\&D is lower than the one in entrants' R\&D as it should be easier for incumbents to undertake international research projects by having employees in different countries working on the same project than for entrants (empirical support for this assumption is supplied by Gertler, Wolfe, and Garkut, 2000; Ramondo, 2009; FernándezRibas, 2010; Guadalupe, Kuzmina, and Thomas, 2012).

The following remarkable results emerge from utilizing heterogeneous technology spillovers. First, the within-country correlation between incumbents' and entrants' innovation probabilities decreases below one. Therefore, the empirically observed moderate correlation between incumbents' and entrants' innovation probabilities is endogenously reproduced. Second, a higher degree of internationalization of R\&D for incumbents (entrants) makes net exports more (less) counter-cyclical, relative to the model with homogeneous technology spillovers. In the data, net exports are highly counter-cyclical. Third, the correlation between exchange rate growth and consumption growth differentials becomes less (more) positive when entrants' (incumbents') R\&D is more international. The empirical counterpart is thus better matched when entrants' R\&D is more international. 


\title{
Heterogeneity in the Internationalization of R\&D: Implications for Anomalies in Finance and Macroeconomics
}

\author{
Patrick Grüning ${ }^{\mathrm{a}, \mathrm{b}}$
}

This version: October 17, 2017

\begin{abstract}
Empirical evidence suggests that investments in research and development (R\&D) by older and larger firms are more spread out internationally than R\&D investments by younger and smaller firms. In this paper, I explore the quantitative implications of this type of heterogeneity by assuming that incumbents, i.e. current monopolists engaging in incremental innovation, have a higher degree of internationalization in their R\&D technologies than entrants, i.e. new firms engaging in radical innovation, in a two-country endogenous growth general equilibrium model. In particular, this assumption allows the model to break the perfect correlation between incumbents' and entrants' innovation probabilities and to match the empirical counterpart exactly.
\end{abstract}

Keywords: Heterogeneous innovation, Technology spillover, Endogenous growth, Creative destruction, International finance

JEL: E22, F31, G12, O30, O41

a Center for Excellence in Finance and Economic Research (CEFER), Bank of Lithuania, Totoriu g. 4, 01121 Vilnius, Lithuania. E-mail and phone: PGruening@lb.lt, +370 52680069.

b Faculty of Economics, Vilnius University, Saulètekio al. 9, II Building, 10222 Vilnius, Lithuania. 


\section{Introduction}

Technology spillovers are important drivers of economic growth. However, the theoretical spillover literature typically relies on endogenous growth expanding variety models with homogeneous innovations only (Coe, Helpman, and Hoffmaister, 1997; Croce, Nguyen, and Schmid, 2015; Santacreu, 2015; Gavazzoni and Santacreu, 2015; Grüning, 2017). In this paper, I do not restrict the model to feature only homogeneous innovations. Instead, I analyze the equilibrium implications of technology spillovers within an endogenous growth Schumpeterian model with heterogeneous innovations by incumbents and entrants.

The model in this article is similar to the one used by Grüning (2017). The only difference is the presence of heterogeneous instead of homogeneous innovations. Small incremental innovations are undertaken by incumbents allowing them to increase their monopoly profits. Entrants undertake large radical innovations and displace incumbents upon a successful innovation, giving rise to "Creative Destruction" effects (Schumpeter, 1934, 1942). Technology spillovers are modeled following Grüning (2017), i.e. both types of innovating firms need to use both countries' final goods to undertake investments in research and development $(\mathrm{R} \& \mathrm{D})$. I use the term technology spillover in the sense that using both countries' goods (instead of only using domestic goods) exposes the domestic economy to a larger extent to foreign productivity shocks.

Specifically, different home bias parameters for the Cobb-Douglas R\&D expenditure bundles of incumbents and entrants are used, allowing heterogeneity in the internationalization of R\&D efforts. To the best of my knowledge, my model is the first one to exploit this kind of heterogeneity. In the benchmark heterogeneous spillover calibration, the home bias parameter in incumbents' $R \& D$ is lower than the one in entrants' $R \& D$. It should be easier for incumbents than for entrants to undertake international research projects by having employees in different countries working on the same project (empirical support for this assumption is supplied by Gertler, Wolfe, and Garkut, 2000; Ramondo, 2009; Fernández-Ribas, 2010; Guadalupe, Kuzmina, and Thomas, 2012).

The following remarkable results emerge from utilizing heterogeneous technology spillovers. First, the within-country correlation between incumbents' and entrants' innovation probabilities decreases below one. Therefore, the empirically observed moderate correlation between incumbents' and entrants' innovation probabilities is endogenously reproduced. Bena, Garlappi, and Grüning (2016) introduce exogenous barriers to entry in a closed one-country economy to achieve this. Second, a higher degree of internationalization of R\&D for incumbents (entrants) makes net exports more (less) counter-cyclical, relative to the model with homogeneous technology spillovers. In the data, net exports are highly counter-cyclical. Third, the correlation between exchange rate growth and consumption 
growth differentials becomes less (more) positive when entrants' (incumbents') R\&D is more international, implying that the empirical counterpart is better matched when entrants' R\&D is more international.

The article is structured as follows. Section 2 briefly outlines the model. The calibration is described in Section 3, and the model-implied moments are discussed in Section 4. Section 5 concludes. Appendix A contains the full model. The model's impulse response functions are depicted and discussed in Appendix B.

\section{Brief Model Description}

This section briefly outlines the model. The full description of the model is found in Appendix A. The model differs from that of Grüning (2017) only in the innovation sector. Grüning (2017) relies on homogeneous innovation by entrants only in an expanding variety endogenous growth model, pioneered by Romer (1990) and applied to asset pricing by Kung and Schmid (2015). Here instead, incumbents engage in incremental innovations and entrants in radical innovations. Hence, the model features heterogeneous innovations in a Schumpeterian endogenous growth model, pioneered by Grossman and Helpman (1991) and Aghion and Howitt (1992). The innovation structure with both incumbents and entrants undertaking R\&D was first analyzed by Acemoglu and Cao (2015) and subsequently applied to asset pricing by Bena, Garlappi, and Grüning (2016).

Specifically, my model features two symmetric countries. Each country is populated by a representative household and two production sectors. The first sector admits a perfectly competitive firm producing the respective country's final good using labor, capital, and a composite of intermediate goods. The monopolistically competitive intermediate goods sector provides a continuum of intermediate goods for final goods production. The monopolists (incumbents) in this sector produce their respective intermediate good and sell it at monopoly price to the final goods firm. They can also engage in incremental innovations. New firms (entrants) try to steal the monopoly from incumbents by inventing a radically better, new product. Therefore, entrants engage in radical innovations. If neither an incremental innovation by the incumbent is successful nor an entrant displaces the incumbent, the incumbent's product's quality depreciates, capturing patent obsolescence. Both incremental and radical innovations improve the quality of the intermediate good, yielding sustainable endogenous growth.

The household which has a preference for leisure, supplies labor endogenously to the final goods firm. Its wage is subject to wage rigidities. Financial markets are domestically and internationally complete and frictionless. Moreover, households and innovating firms 
trade final goods, i.e. the households' consumption and both incumbents' and potential entrants' effective R\&D expenditures are given as Cobb-Douglas aggregates of both final goods. Domestic entrants are only allowed to enter the domestic intermediate goods sector. Furthermore, incumbents only produce intermediate goods for the final goods sector in their respective countries. The assumption that R\&D expenditures are Cobb-Douglas aggregates over both final goods introduces technology spillovers, as in Grüning (2017).

\section{Calibration}

Four different calibrations of the model are described in this section. Table 1 contains the four sets of parameters. All calibrations are annual. The first calibration features no technology spillovers. Hence, the home bias parameters in both incumbents' and entrants' $R \& D$ expenditure bundles are set to the limiting value of 1 , i.e. $\phi_{\mathrm{I}}=\phi_{\mathrm{E}}=1$. The second calibration features homogeneous technology spillovers, i.e. $\phi_{\mathrm{I}}=\phi_{\mathrm{E}}=0.90$, so that $10 \%$ of the goods used in both incumbents' and entrants' R\&D are from the foreign country. The final two calibrations feature heterogeneous technology spillovers. In the third calibration, I assume $\phi_{\mathrm{I}}=0.85$ and $\phi_{\mathrm{E}}=0.95$. Thus, incumbents have a higher degree of internationalization in $\mathrm{R} \& \mathrm{D}$ than entrants. This captures that it should be easier for incumbents than for entrants to undertake international research projects by having employees in different countries working on the same project. Incumbents have more capital available to build such a global infrastructure. This assumption is supported by empirical evidence given in Ramondo (2009) as well as Guadalupe, Kuzmina, and Thomas (2012) that multinational firms are successful in spreading R\&D benefits across countries. Furthermore, research activities by bigger and more established firms, proxied by incumbents in the model, are undertaken to a larger extent internationally than research by smaller and younger firms, which are proxied by entrants. Empirical studies which document this fact are FernándezRibas (2010) and Gertler, Wolfe, and Garkut (2000). Finally, I assume $\phi_{\mathrm{I}}=0.95$ and $\phi_{\mathrm{E}}=0.85$ in calibration [4]. This final calibration is analyzed for completeness.

The innovation sizes $\kappa_{\mathrm{I}}$ and $\kappa_{\mathrm{E}}$ and the depreciation rate of technology capital $\kappa_{\mathrm{D}}$ are equal to the estimates from Bena, Garlappi, and Grüning (2016): $\kappa_{\mathrm{D}}=0.09, \kappa_{\mathrm{I}}=1.25$, $\kappa_{\mathrm{E}}=2.50$. Moreover, I also set the R\&D productivity elasticities equal to the ones used by Bena, Garlappi, and Grüning (2016), i.e. $\omega_{\mathrm{I}}=0.8933$ and $\omega_{\mathrm{E}}=0.8607$. In all calibrations, the R\&D productivity shift parameters $\eta_{\mathrm{I}}$ and $\eta_{\mathrm{E}}$ are set so that the ratio of the average innovation probability of entrants to the sum of the average innovation probabilities of incumbents and entrants is equal to the average of the empirical counterpart, i.e. the quantity which Bena, Garlappi, and Grüning (2016) call the rate of radical innovation, and so that the average consumption growth rate is two percentage points. 
Table 1: Calibrations

\begin{tabular}{|c|c|c|c|c|c|}
\hline Parameter & Description & [1] & [2] & [3] & [4] \\
\hline$\beta$ & Subjective discount factor & 0.984 & 0.984 & 0.984 & 0.984 \\
\hline$\gamma$ & Risk aversion & 10 & 10 & 10 & 10 \\
\hline$\psi$ & Elasticity of intertemporal substitution & 1.85 & 1.85 & 1.85 & 1.85 \\
\hline$f$ & Elasticity of labor supply & 0.7 & 0.7 & 0.7 & 0.7 \\
\hline$\tau$ & Weight of consumption in utility bundle & 0.1101 & 0.1091 & 0.1086 & 0.1096 \\
\hline$\alpha$ & Capital share & 0.35 & 0.35 & 0.35 & 0.35 \\
\hline$\xi$ & Intermediate goods share & 0.5 & 0.5 & 0.5 & 0.5 \\
\hline$\nu$ & Elasticity of substitution between intermediate goods & 1.65 & 1.65 & 1.65 & 1.65 \\
\hline$\delta$ & Depreciation rate of physical capital & 0.08 & 0.08 & 0.08 & 0.08 \\
\hline$\zeta$ & Investment adjustment costs parameter & 0.7 & 0.7 & 0.7 & 0.7 \\
\hline$\rho_{a}$ & Persistence of country-specific technology shocks & 0.96 & 0.96 & 0.96 & 0.96 \\
\hline$\sigma_{a}$ & Volatility of country-specific technology shocks & 0.0175 & 0.0173 & 0.0180 & 0.0167 \\
\hline$\rho_{z}$ & Persistence of common technology shock & 0.96 & 0.96 & 0.96 & 0.96 \\
\hline$\sigma_{z}$ & Volatility of common technology shock & 0.0171 & 0.0171 & 0.0166 & 0.0173 \\
\hline$\rho_{\varphi}$ & Persistence of volatility shocks & 0.987 & 0.987 & 0.987 & 0.987 \\
\hline$\sigma_{\varphi}$ & Volatility of volatility shocks & 0.02 & 0.02 & 0.02 & 0.02 \\
\hline--- & Depreciation rate of technology capital & $-\overline{0.09}$ & $-\overline{0}-\overline{09}$ & $--\overline{0}$ & $-\overline{0}-\overline{0}$ \\
\hline$\kappa_{\mathrm{I}}$ & Incremental innovation size & 1.25 & 1.25 & 1.25 & 1.25 \\
\hline$\kappa_{\mathrm{E}}$ & Radical innovation size & 2.50 & 2.50 & 2.50 & 2.50 \\
\hline$\eta_{\mathrm{I}}$ & Incumbents' R\&D productivity shift parameter & 6.9890 & 9.4504 & 10.3742 & 8.3962 \\
\hline$\omega_{\mathrm{I}}$ & Incumbents' R\&D productivity elasticity & 0.8933 & 0.8933 & 0.8933 & 0.8933 \\
\hline$\eta_{\mathrm{E}}$ & Entrants' R\&D productivity shift parameter & 0.8235 & 1.1018 & 0.9941 & 1.1921 \\
\hline$\omega_{\mathrm{E}}$ & Entrants' R\&D productivity elasticity & 0.8607 & 0.8607 & 0.8607 & 0.8607 \\
\hline $\bar{\mu}$ & Wage stickiness parameter & $0 . \overline{35}$ & $-\overline{0}-\overline{35}$ & $-\overline{--}-\overline{35}$ & 0.35 \\
\hline$-\overline{\phi_{\mathrm{C}}}$ & Home bias in consumption & $0 . \overline{9}$ & $\overline{0} \overline{9} \overline{5}$ & $-\overline{-} \overline{5}$ & $0 . \overline{9}{ }^{-}$ \\
\hline$\phi_{\mathrm{I}}$ & Home bias in incumbents' $R \& D$ investment & 1 & 0.90 & 0.85 & 0.95 \\
\hline$\phi_{\mathrm{E}}$ & Home bias in entrants' R\&D investment & 1 & 0.90 & 0.95 & 0.85 \\
\hline
\end{tabular}

This table reports the parameters used in the four calibrations of the model, as outlined in Section 3. The calibrations are annual and countries are symmetric in all calibrations. Calibration [1] is the economy without technology spillovers; calibration [2] is the economy with homogeneous technology spillovers; calibration [3] features heterogeneous technology spillovers with incumbents using a higher share of foreign goods; calibration [4] also features heterogeneous technology spillovers but with entrants using a higher share of foreign goods. The numbers in bold highlight the parameters that are different in those four calibrations.

Similar to Grüning (2017), the volatilities of the productivity shocks $\sigma_{a}$ and $\sigma_{z}$ are pinned down by requiring that the model matches an output growth volatility of 2.15 percentage points and a cross-country output growth correlation of 0.51 across all calibrations. The remaining parameters are set identically or pinned down similarly to Grüning (2017). Note that the annual versions of the quarterly parameters therein are used.

\section{Results}

This section discusses the simulated moments of the four aforementioned calibrations. The model is solved in Dynare ++4.4 .3 using third-order perturbations around the stochastic steady state. I use 1,500 simulations, and each simulation is 150 years long, from which the first 50 years are not used to compute the moments. Table 2 reports country-specific 
moments and Table 3 international moments. The empirical moments in the "Data" column are from Grüning (2017) for all quantities except innovation probabilities, which are from Bena, Garlappi, and Grüning (2016). Details on the data are given in these articles. Looking first at the results of the benchmark calibration [1], one can see that the model matches well the average innovation probabilities of incumbents and entrants but reproduces only about half of the observed volatilities of innovation probabilities, similar to Bena, Garlappi, and Grüning (2016). Moreover, the model counter-factually produces a perfect correlation between incumbents' and entrants' innovation probabilities. The volatilities of macroeconomic growth rates do not match the empirical counterparts precisely, but they are also not unrealistic. The average risk-free rate and equity excess returns are well in line with the data, but the volatilities are too low. Turning to international moments, the model is qualitatively in line with the negative correlation between net exports and output. Moreover, it comes close to the empirical counterpart for exchange rate growth volatility and the correlation between exchange rate growth and consumption growth differentials (reconciling the Backus and Smith (1993) anomaly). The model fails to produce a low uncovered interest parity coefficient. With the exception of output growth, which is targeted in the calibration, the cross-country correlations of growth rates are all a bit too high. Therefore, the model cannot explain the quantity anomaly of Backus, Kehoe, and Kydland (1994). The cross-country correlations of the risk-free rates and equity excess returns, however, are explained relatively well.

Next, homogeneous technology spillovers are included in calibration [2]. Relative to calibration [1], country-specific moments do not change much. However, international moments are significantly affected. Net exports become slightly more counter-cyclical. Exchange rate growth volatility drops significantly, in line with the empirical evidence of Gavazzoni and Santacreu (2015) that countries which trade more with each other display lower exchange rate variability. The Backus and Smith (1993) correlation increases significantly to 0.72 , further away from the empirical counterpart. Consumption growth, R\&D expenditure growth, expected consumption growth, and innovation probabilities become more highly correlated across countries. The same holds for the risk-free rates, whereas equity excess returns become slightly less correlated using the first definition of the aggregate dividends and significantly less correlated using the second definition.

Comparing these results with the results of calibrations [1] and [2] in Grüning (2017) reveals that whether one chooses a heterogeneous innovation Schumpeterian endogenous growth model or a homogeneous innovation expanding variety endogenous growth model does not matter much for the moments of aggregate quantities, with and without technology spillovers. 
Table 2: Country-specific macro quantities and asset prices

\begin{tabular}{|c|c|c|c|c|c|}
\hline Moment & Data & {$[1]$} & {$[2]$} & {$[3]$} & [4] \\
\hline & \multicolumn{5}{|c|}{ Macroeconomic quantities } \\
\hline $\mathbb{E}[\Delta y]$ & 2.88 & 2.00 & 2.00 & 2.00 & 2.00 \\
\hline $\mathbb{E}[\Delta c]$ & 1.91 & 2.00 & 2.00 & 2.00 & 2.00 \\
\hline $\mathbb{E}\left[\Phi^{\mathrm{I}}\right]$ & 13.86 & 14.35 & 14.35 & 14.31 & 15.35 \\
\hline $\mathbb{E}\left[\hat{\Phi}^{\mathrm{E}}\right]$ & 3.82 & 3.87 & 3.88 & 3.88 & 3.93 \\
\hline$\sigma_{\Delta y}$ & 2.15 & 2.15 & 2.15 & 2.15 & 2.15 \\
\hline$\sigma_{\Delta c}$ & 1.86 & 1.15 & 1.07 & 1.08 & 1.09 \\
\hline$\sigma_{\Delta i}$ & 5.57 & 2.12 & 2.12 & 2.08 & 2.14 \\
\hline$\sigma_{\Delta l}$ & 0.61 & 1.07 & 1.05 & 1.03 & 1.07 \\
\hline$\sigma_{\Delta w}$ & 0.15 & 1.46 & 1.43 & 1.44 & 1.42 \\
\hline$\sigma_{\Delta s}$ & 2.93 & 4.41 & 4.35 & 4.28 & 4.37 \\
\hline$\sigma_{\Phi^{\mathrm{I}}}$ & 2.20 & 1.21 & 1.14 & 1.18 & 5.64 \\
\hline$\sigma_{\hat{\Phi}^{\mathrm{E}}}$ & 0.56 & 0.24 & 0.23 & 0.27 & 0.50 \\
\hline$\sigma\left(\mathbb{E}_{t}\left[\Delta c_{t+1}\right]\right)$ & - & 0.61 & 0.57 & 0.54 & 0.62 \\
\hline$\sigma\left(\mathbb{E}_{t}\left[\Delta c_{t+1}\right]\right) / \sigma\left(\Delta c_{t}\right)$ & - & 0.47 & 0.47 & 0.46 & 0.48 \\
\hline $\operatorname{corr}\left(\mathbb{E}_{t}\left[\Delta c_{t+1}\right], \Delta c_{t}\right)$ & - & 0.83 & 0.86 & 0.83 & 0.83 \\
\hline \multirow[t]{2}{*}{$\operatorname{corr}\left(\Phi^{\mathrm{I}}, \hat{\Phi}^{\mathrm{E}}\right)$} & 0.47 & 1.00 & 1.00 & 0.47 & -0.22 \\
\hline & \multicolumn{5}{|c|}{ Asset prices } \\
\hline $\mathbb{E}\left[r_{f}\right]$ & 1.68 & 1.93 & 1.89 & 1.89 & 1.95 \\
\hline$\sigma_{r_{f}}$ & 2.37 & 0.25 & 0.23 & 0.22 & 0.26 \\
\hline $\mathbb{E}\left[r_{a}^{l e v}-r_{f}\right]$ & 3.07 & 2.26 & 2.43 & 2.26 & 2.36 \\
\hline$\sigma_{r_{a}^{l e v}-r_{f}}$ & 17.85 & 6.20 & 6.24 & 6.28 & 6.01 \\
\hline $\mathbb{E}\left[\widetilde{r}_{a}^{l e v}-r_{f}\right]$ & 3.07 & 1.65 & 1.72 & 1.68 & 1.66 \\
\hline$\sigma_{\widetilde{r}_{a}^{l e v}-r_{f}}$ & 17.85 & 4.14 & 4.38 & 4.15 & 4.21 \\
\hline
\end{tabular}

This table reports the simulated moments for country-specific macroeconomic quantities and asset prices of the model outlined in Section 2 and the four calibrations [1]-[4] reported in Table 1. Specifically, the table reports average log output growth $\mathbb{E}[\Delta y]$; average log consumption growth $\mathbb{E}[\Delta c]$; average incumbents' innovation probability $\mathbb{E}\left[\Phi^{\mathrm{I}}\right]$; average entrants' innovation probability $\mathbb{E}\left[\hat{\Phi}^{\mathrm{E}}\right]$; the volatilities of log output growth $\sigma_{\Delta y}, \log$ consumption growth $\sigma_{\Delta c}$, log investment growth $\sigma_{\Delta i}, \log$ labor growth $\sigma_{\Delta l}, \log$ wage growth $\sigma_{\Delta w}$, log total R\&D expenditure growth $\sigma_{\Delta s}$, incumbents' innovation probability $\sigma_{\Phi \mathrm{I}}$, entrants' innovation probability $\sigma_{\hat{\mathrm{\Phi}} \mathrm{E}}$, and expected $\log$ consumption growth $\sigma\left(\mathbb{E}_{t}\left[\Delta c_{t+1}\right]\right)$; the ratio of the volatility of expected consumption growth to the one of realized consumption growth $\sigma\left(\mathbb{E}_{t}\left[\Delta c_{t+1}\right]\right) / \sigma\left(\Delta c_{t}\right)$; the correlation between expected consumption growth and realized consumption growth $\operatorname{corr}\left(\mathbb{E}_{t}\left[\Delta c_{t+1}\right], \Delta c_{t}\right)$; the correlation between incumbents' and entrants' innovation probability $\operatorname{corr}\left(\Phi^{\mathrm{I}}, \hat{\Phi}^{\mathrm{E}}\right)$; the average riskfree rate $\mathbb{E}\left[r_{f}\right]$; the volatility of the risk-free rate $\sigma_{r_{f}}$; and, finally, the average levered market risk premium and the volatility of the levered market excess returns for two definitions of the aggregate dividend given in Equations (A.44) and (A.45), i.e. $\mathbb{E}\left[r_{a}^{\text {lev }}-r_{f}\right], \mathbb{E}\left[\widetilde{r}_{a}^{l e v}-r_{f}\right], \sigma_{r_{a}^{l e v}-r_{f}}$, and $\sigma_{\widetilde{r}_{a}^{l e v}-r_{f}}$. Total R\&D expenditures in the home country are defined by $S_{I, h, t}+S_{E, h, t}+P_{t}\left(S_{I, f, t}^{a}+S_{E, f, t}\right)$. Market excess returns are levered following Croce (2014) by computing $\phi_{\text {lev }}\left(r_{a}-r_{f}\right)$ and $\phi_{\text {lev }}\left(\widetilde{r}_{a}-r_{f}\right)$ with $\phi_{\text {lev }}=2$. The moments of the model and the data are annual. All moments in the table are reported in percentage points except for $\sigma\left(\mathbb{E}_{t}\left[\Delta c_{t+1}\right]\right) / \sigma\left(\Delta c_{t}\right)$ and $\operatorname{corr}\left(\mathbb{E}_{t}\left[\Delta c_{t+1}\right], \Delta c_{t}\right)$. 
Table 3: International quantities

\begin{tabular}{rccccc}
\hline Moment & Data & {$[1]$} & {$[2]$} & {$[3]$} & {$[4]$} \\
\hline $\mathbb{E}[$ Imports $/ Y]$ & 11.27 & 1.78 & 3.67 & 3.30 & 4.04 \\
$\mathbb{E}[$ Exports $/ Y]$ & 9.24 & 1.78 & 3.67 & 3.30 & 4.04 \\
$\operatorname{corr}(N X / Y, Y)$ & -0.84 & -0.21 & -0.26 & -0.39 & 0.10 \\
$\sigma_{\Delta e}$ & 6.47 & 4.12 & 1.66 & 1.22 & 2.83 \\
$\operatorname{corr}\left(\Delta e, \Delta c-\Delta c^{*}\right)$ & -0.05 & 0.10 & 0.72 & 0.96 & 0.29 \\
$\mathbb{E}\left[\beta_{U I P}\right]$ & 0.01 & 0.86 & 0.86 & 0.91 & 1.23 \\
$\operatorname{corr}\left(\Delta c, \Delta c^{*}\right)$ & 0.26 & 0.52 & 0.63 & 0.54 & 0.63 \\
$\operatorname{corr}\left(\Delta y, \Delta y^{*}\right)$ & 0.51 & 0.51 & 0.51 & 0.51 & 0.51 \\
$\operatorname{corr}\left(\Delta i, \Delta i^{*}\right)$ & 0.35 & 0.65 & 0.63 & 0.65 & 0.57 \\
$\operatorname{corr}\left(\Delta l, \Delta l^{*}\right)$ & 0.33 & 0.56 & 0.55 & 0.60 & 0.50 \\
$\operatorname{corr}\left(\Delta w, \Delta w^{*}\right)$ & 0.01 & 0.48 & 0.51 & 0.46 & 0.54 \\
$\operatorname{corr}\left(\Delta s, \Delta s^{*}\right)$ & 0.31 & 0.52 & 0.66 & 0.71 & 0.57 \\
$\operatorname{corr}\left(\mathbb{E}_{t}\left[\Delta c_{t+1}\right], \mathbb{E}_{t}\left[\Delta c_{t+1}^{*}\right]\right)$ & - & 0.55 & 0.76 & 0.88 & 0.54 \\
$\operatorname{corr}\left(\Phi^{\mathrm{I}}, \Phi^{\mathrm{I}, *}\right)$ & - & 0.54 & 0.69 & 0.51 & -0.20 \\
$\operatorname{corr}\left(\hat{\Phi}^{\mathrm{E}}, \hat{\Phi}^{\mathrm{E}, *}\right)$ & - & 0.54 & 0.69 & 0.19 & -0.32 \\
$\operatorname{corr}\left(r_{f}, r_{f}^{*}\right)$ & 0.64 & 0.52 & 0.59 & 0.63 & 0.54 \\
$\cos$ & & & \\
$\operatorname{corr}\left(r_{a}^{l e v}-r_{f}, r_{a}^{*, l e v}-r_{f}^{*}\right)$ & 0.72 & 0.84 & 0.81 & 0.71 & 0.89 \\
$\operatorname{corr}\left(\widetilde{r}_{a}^{l e v}-r_{f}, \widetilde{r}_{a}^{*, l e v}-r_{f}^{*}\right)$ & 0.72 & 0.64 & 0.45 & 0.57 & 0.52 \\
$\operatorname{corr}\left(\mathbb{M}, \mathbb{M}^{*}\right)$ & - & 0.99 & 1.00 & 1.00 & 1.00 \\
\hline
\end{tabular}

This table reports the simulated moments for international macroeconomic and asset pricing quantities of the model outlined in Section 2 and the four calibrations [1]-[4] reported in Table 1. Specifically, the table reports the average total imports to output ratio of the home country $\mathbb{E}[\operatorname{Imports} / Y]$; the average total exports to output ratio of the home country $\mathbb{E}[$ Exports $/ Y]$; the correlation between the net exports to output ratio with output of the home country $\operatorname{corr}(N X / Y, Y)$; the volatility of exchange rate growth $\sigma_{\Delta e}$; the correlation between exchange rate growth and log consumption growth differentials $\operatorname{corr}\left(\Delta e, \Delta c-\Delta c^{*}\right)$; the average beta from uncovered interest parity time-series regressions $\mathbb{E}\left[\beta_{U I P}\right]$ using the regression equation $\Delta e_{t+1}=\beta_{U I P} \cdot\left(r_{f, t}^{\text {bundle }}-r_{f, t}^{*, \text { bundle }}\right)+\varepsilon_{t}$, where $r_{f, t}^{\text {bundle }}=-\log \left(\mathbb{E}_{t}\left[\mathbb{M}_{t, t+1}\right]\right)$ and $r_{f, t}^{*, \text { bundle }}=$ $-\log \left(\mathbb{E}_{t}\left[\mathbb{M}_{t, t+1}^{*}\right]\right)$; and the cross-country correlations of $\log$ consumption growth $\operatorname{corr}\left(\Delta c, \Delta c^{*}\right)$, $\log$ output growth $\operatorname{corr}\left(\Delta y, \Delta y^{*}\right), \log$ investment growth $\operatorname{corr}\left(\Delta i, \Delta i^{*}\right), \log$ labor growth $\operatorname{corr}\left(\Delta l, \Delta l^{*}\right), \log$ wage growth $\operatorname{corr}\left(\Delta w, \Delta w^{*}\right)$, log total R\&D expenditure growth $\operatorname{corr}\left(\Delta s, \Delta s^{*}\right)$, expected log consumption growth $\operatorname{corr}\left(\mathbb{E}_{t}\left[\Delta c_{t+1}\right], \mathbb{E}_{t}\left[\Delta c_{t+1}^{*}\right]\right)$, incumbents' innovation probabilities $\operatorname{corr}\left(\Phi^{\mathrm{I}}, \Phi^{\mathrm{I},{ }^{*}}\right)$, entrants' innovation probabilities $\operatorname{corr}\left(\hat{\Phi}^{\mathrm{E}}, \hat{\Phi}^{\mathrm{E}, *}\right)$, risk-free rates $\operatorname{corr}\left(r_{f}, r_{f}^{*}\right)$, levered excess market returns in two variants defined in Equations (A.44) and (A.45), i.e. $\operatorname{corr}\left(r_{a}^{l e v}-r_{f}, r_{a}^{*}, l e v-r_{f}^{*}\right)$ and $\operatorname{corr}\left(\widetilde{r}_{a}^{l e v}-r_{f}, \widetilde{r}_{a}^{*}, l e v-r_{f}^{*}\right)$, and of the pricing kernels corr $\left(\mathbb{M}, \mathbb{M}^{*}\right)$. Total R\&D expenditures in the home country are defined by $S_{I, h, t}+S_{E, h, t}+P_{t}\left(S_{I, f, t}+S_{E, f, t}\right)$ and in the foreign country by $S_{I, f, t}^{*}+S_{E, f, t}^{*}+\left(S_{I, h, t}^{*}+S_{E, h, t}^{*}\right) / P_{t}$. Market excess returns are levered following Croce (2014) by computing $\phi_{\text {lev }}\left(r_{a}-r_{f}\right)$ and $\phi_{\text {lev }}\left(\widetilde{r}_{a}-r_{f}\right)$ with $\phi_{l e v}=2$. The moments of the model and the data are annual. Means and volatilities in the table are reported in percentage points.

The interesting results of this paper emerge when technology spillovers are assumed to be heterogeneous in calibrations [3] and [4]. The empirically more plausible calibration [3], where incumbents' R\&D is more internationalized than entrants' $R \& D$, is discussed first. Due to heterogeneous exposure to productivity shocks of both countries, incumbents' 
and entrants' innovation probabilities within a country are no longer perfectly positively correlated. Specifically, the empirical counterpart of 0.47 is now matched exactly. Hence, heterogeneous technology spillovers provide an endogenous mechanism to explain this moderate correlation. Bena, Garlappi, and Grüning (2016) introduce exogenous stochastic barriers to entry to resolve this anomaly. Here, I provide an alternative, endogenous explanation for this anomaly. Net exports are also the most counter-cyclical among all calibrations matching the data best (the model-implied moment is -0.39). However, the Backus and Smith (1993) correlation and the cross-country correlation of R\&D expenditures increase further.

Calibration [4] features a higher internationalization of entrants than of incumbents. In general, this calibration matches the data worse than calibration [3]. The correlation of incumbents' and entrants' innovation probabilities is -0.22 . Net exports become procyclical in this calibration, but the Backus and Smith (1993) correlation is considerably lower than in the case of homogeneous technology spillovers.

A brief discussion of how heterogeneous technology spillovers affect the international transmission of shocks and thus why calibration [3] can match the empirically observed correlation between incumbents' and entrants' innovation probabilities can be found in Appendix B.

\section{Conclusion}

This study analyzes the general equilibrium implications of heterogeneity in the internationalization of R\&D efforts. Specifically, incumbents and entrants undertaking incremental innovations and radical innovations, respectively, are subject to different home bias parameters in bundling both countries' final goods for their R\&D investments. In line with empirical evidence, it is assumed that incumbents face a lower home bias and thus a higher degree of internationalization than entrants. This difference in the internationalization of $\mathrm{R} \& \mathrm{D}$ endogenously produces an empirically plausible moderate correlation between incumbents' and entrants' innovation probabilities, it makes net exports more counter-cyclical, as in the data, and it leads to a further counter-factual increase in the correlation between exchange rate growth and consumption growth differentials.

\section{Acknowledgments}

I would like to thank Michael Donadelli and the seminar participants at the Bank of Lithuania for their valuable comments. The views expressed herein are solely those of the 
author and do not necessarily reflect the views of the Bank of Lithuania or the Eurosystem. Funding: This work was supported (in terms of both research and financial support) by the Research Center SAFE, funded by the State of Hessen initiative for research LOEWE. 


\section{References}

Acemoglu, D., And D. V. CaO (2015): "Innovation by entrants and incumbents," Journal of Economic Theory, 157, 255-294.

Aghion, P., And P. Howitt (1992): "A Model of Growth Through Creative Destruction," Econometrica, 60(2), 323-351.

Backus, D., P. J. Kehoe, And F. E. Kydland (1994): "Dynamics of the trade balance and the terms of trade: The j-curve?," American Economic Review, 84(1), 84-103.

Backus, D., And G. Smith (1993): "Consumption and real exchange rates in dynamic exchange economie with nontraded goods," Journal of International Economics, 35(3-4), 297-316.

Bena, J., L. Garlappi, And P. GrÜning (2016): "Heterogeneous Innovation, Firm Creation and Destruction, and Asset Prices," Review of Asset Pricing Studies, 6(1), 46-87.

Coe, D. T., E. Helpman, And A. W. Hoffmaister (1997): "North-South R\&D spillovers," Economic Journal, 107, 134-149.

Colacito, R., M. M. Croce, S. Ho, And P. Howard (2017): "BKK the EZ Way: International Long-Run Growth News and Capital Flows," Working Paper.

Croce, M. M. (2014): "Long-Run Productivity Risk: A New Hope for Production-Based Asset Pricing?," Journal of Monetary Economics, 66, 13-31.

Croce, M. M., T. T. Nguyen, And L. Schmid (2015): "Global Entropy," Working Paper.

Epstein, L. G., And S. Zin (1989): "Substitution, Risk Aversion, and the Temporal Behavior of Consumption Growth and Asset Returns: A Theoretical Framework," Econometrica, 57(4), 937-969.

Fernández-Ribas, A. (2010): "International Patent Strategies of Small and Large Firms: An Empirical Study of Nanotechnology," Review of Policy Research, 27(4), 457-473.

Gavazzoni, F., And A. M. Santacreu (2015): "International R\&D Spillovers and Asset Prices," FRB St. Louis Working Paper No. 2015-41.

Gertler, M. S., D. A. Wolfe, And D. Garkut (2000): "No place like home? The embeddedness of innovation in a regional economy," Review of International Political Economy, 7(4), 688-718.

Grossman, G. M., And E. Helpman (1991): "Quality Ladders in the Theory of Growth," Review of Economic Studies, 58(1), 43-61.

GRÜNING, P. (2017): "International endogenous growth, macro anomalies, and asset prices," Journal of Economic Dynamics and Control, 78, 118-148. 
Guadalupe, M., O. Kuzmina, And C. Thomas (2012): "Innovation and Foreign Ownership," American Economic Review, 102(7), 3594-3627.

Jermann, U. J. (1998): "Asset Pricing in production economies," Journal of Monetary Economics, 41(2), 257-275.

Kung, H., And L. Schmid (2015): "Innovation, growth, and asset prices," Journal of Finance, 70(3), 1001-1037.

Ramondo, N. (2009): "Foreign Plants and Industry Productivity: Evidence from Chile," Scandinavian Journal of Economics, 111(4), 789-809.

Romer, P. M. (1990): "Endogenous Technological Change," Journal of Political Economy, 98(5), $71-102$.

Santacreu, A. M. (2015): "Innovation, Diffusion, and Trade: Theory and Measurement," Journal of Monetary Economics, 75, 1-20.

Schumpeter, J. A. (1934): The Theory of Economic Development. Harvard University Press. (1942): "Creative destruction," Capitalism, socialism and democracy.

Uhlig, H. (2007): "Explaining Asset Prices with External Habits and Wage Rigidities in a DSGE Model," American Economic Review, 97(2), 239-243.

WeIL, P. (1990): "Nonexpected Utility in Macroeconomics," Quarterly Journal of Economics, 105(1), 29-42. 


\section{A Detailed Model Description and Deviations}

The exposition of the model closely follows Grüning (2017). In what follows, home country's quantities do not carry any superscript and foreign country's quantities carry a superscript asterisk.

\section{A.1 Households}

The representative households in the home and foreign country have recursive preferences as in Epstein and Zin (1989) and Weil (1990) over the utility flow $u_{t}$ and $u_{t}^{*}$, respectively:

$$
\begin{aligned}
U_{t} & =\left\{(1-\beta)\left(u_{t}\right)^{\frac{1-\gamma}{\theta}}+\beta\left(\mathbb{E}_{t}\left[\left(U_{t+1}\right)^{1-\gamma}\right]\right)^{\frac{1}{\theta}}\right\}^{\frac{\theta}{1-\gamma}}, \\
U_{t}^{*} & =\left\{(1-\beta)\left(u_{t}^{*}\right)^{\frac{1-\gamma}{\theta}}+\beta\left(\mathbb{E}_{t}\left[\left(U_{t+1}^{*}\right)^{1-\gamma}\right]\right)^{\frac{1}{\theta}}\right\}^{\frac{\theta}{1-\gamma}},
\end{aligned}
$$

where $\gamma$ is the coefficient of relative risk aversion, $\beta$ the subjective time preference parameter, $\theta=$ $(1-\gamma) /\left(1-\frac{1}{\psi}\right)$, and $\psi$ the elasticity of intertemporal substitution. The households choose the amount of the home final good $\mathcal{Y}_{h, t}$ and of the foreign final good $\mathcal{Y}_{f, t}$ for consumption, and the amount of labor $L_{t}$ to maximize lifetime utility. The utility flows $u_{t}, u_{t}^{*}$ of both countries are given by:

$$
\begin{aligned}
& u_{t}=\left[\tau\left(C_{t}\right)^{1-\frac{1}{f}}+(1-\tau)\left(\left(N_{t}\right)^{\phi_{\mathrm{C}}}\left(N_{t}^{*}\right)^{1-\phi_{\mathrm{C}}}\left(\bar{L}-L_{t}\right)\right)^{1-\frac{1}{f}}\right]^{\frac{1}{1-\frac{1}{f}}}, \\
& u_{t}^{*}=\left[\tau\left(C_{t}^{*}\right)^{1-\frac{1}{f}}+(1-\tau)\left(\left(N_{t}^{*}\right)^{\phi_{\mathrm{C}}}\left(N_{t}\right)^{1-\phi_{\mathrm{C}}}\left(\bar{L}-L_{t}^{*}\right)\right)^{1-\frac{1}{f}}\right]^{\frac{1}{1-\frac{1}{f}}} .
\end{aligned}
$$

The parameter $f$ determines the elasticity of labor supply, $\bar{L}$ denotes the total time endowment of households, and the parameter $\tau$ determines the weight of consumption in the utility bundle. The Cobb-Douglas aggregates $\left(Q_{t}\right)^{\phi_{\mathrm{C}}}\left(Q_{t}^{*}\right)^{1-\phi_{\mathrm{C}}}$ and $\left(Q_{t}^{*}\right)^{\phi_{\mathrm{C}}}\left(Q_{t}\right)^{1-\phi_{\mathrm{C}}}$ of the aggregate quality of intermediate goods $Q_{t}$ and $Q_{t}^{*}$ in the home and the foreign country, respectively, are a measure for the standards of living and included in the definition of the utility bundles to ensure stationarity of the normalized equilibrium system. The dynamics of $Q_{t}$ and $Q_{t}^{*}$ are derived below in Section A.4. In the definitions above, the consumption bundles $C_{t}, C_{t}^{*}$ of both countries are given by:

$$
C_{t}=\left(\mathcal{Y}_{h, t}\right)^{\phi_{\mathrm{C}}}\left(\mathcal{Y}_{f, t}\right)^{1-\phi_{\mathrm{C}}}, \quad C_{t}^{*}=\left(\mathcal{Y}_{f, t}^{*}\right)^{\phi_{\mathrm{C}}}\left(\mathcal{Y}_{h, t}^{*}\right)^{1-\phi_{\mathrm{C}}}
$$

Home bias in consumption is captured by assuming $\phi_{\mathrm{C}}>0.5$. Market clearing conditions dictate that the net output of each country's final good available for consumption $\mathcal{Y}_{t}$ is allocated among both households (see Equation (A.43) for the definition of net output):

$$
\mathcal{Y}_{t}=\mathcal{Y}_{h, t}+\mathcal{Y}_{h, t}^{*}, \quad \mathcal{Y}_{t}^{*}=\mathcal{Y}_{f, t}^{*}+\mathcal{Y}_{f, t}
$$

My assumption of complete and frictionless financial markets for trading final goods across countries implies that there is a complete set of Arrow-Debreu securities available to households in both countries. The prices of these claims are denoted by $B_{t+1}\left(\chi_{t+1}\right)$ where $\chi_{t+1}$ is the state of the economy at time $t+1$. If a household holds one unit of $B_{t+1}\left(\chi_{t+1}\right)$ between time $t$ and $t+1$, it receives one unit of the home country's final good if the economy is in state $\chi_{t+1}$ at time $t+1$ and zero otherwise. Country $k$ 's household's holdings of these assets are given by $A_{t+1}\left(\chi_{t+1}\right)$. Therefore, the budget constraints of both 
countries' households denoted in home final good units are given by:

$$
\begin{aligned}
& \mathcal{Y}_{h, t}+P_{t} \mathcal{Y}_{f, t}+\int_{\chi_{t+1}} A_{t+1}\left(\chi_{t+1}\right) B_{t+1}\left(\chi_{t+1}\right)=A_{t}+\mathcal{Y}_{t}=A_{t}+D_{a, t}+W_{t} L_{t}-S_{E, h, t}-S_{E, h, t}^{*}, \\
& P_{t} \mathcal{Y}_{f, t}^{*}+\mathcal{Y}_{h, t}^{*}+\int_{\chi_{t+1}} A_{t+1}^{*}\left(\chi_{t+1}\right) B_{t+1}\left(\chi_{t+1}\right)=A_{t}^{*}+P_{t} \mathcal{Y}_{t}^{*}=A_{t}^{*}+P_{t}\left(D_{a, t}^{*}+W_{t} L_{t}^{*}-S_{E, f, t}^{*}-S_{E, f, t}\right) .
\end{aligned}
$$

$P_{t}$ denotes the terms of trade or, equivalently, the price of the foreign final good in home final good units. This price is determined by:

$$
P_{t}=\frac{1-\phi_{\mathrm{C}}}{\phi_{\mathrm{C}}} \frac{\mathcal{Y}_{h, t}}{\mathcal{Y}_{f, t}}
$$

An important quantity in the international consumption allocation problem is the international consumption allocation factor $Z_{t}$ measuring the relative performance of the home country to the foreign country. It is determined by the following recursion:

$$
Z_{t}=Z_{t-1} \frac{\mathbb{M}_{t-1, t}}{\mathbb{M}_{t-1, t}^{*}}\left(\frac{u_{t} / u_{t-1}}{u_{t}^{*} / u_{t-1}^{*}}\right)^{\frac{1}{f}}\left(\frac{C_{t} / C_{t-1}}{C_{t}^{*} / C_{t-1}^{*}}\right)^{1-\frac{1}{f}} .
$$

$Z_{t}>1$ implies that the home country's household currently consumes more than the foreign country's one and is thus relatively richer. Due to financial markets being complete, exchange rate growth $\Delta e_{t}$ is pinned down by the following condition as in Colacito, Croce, Ho, and Howard (2017):

$$
\Delta e_{t}=\ln \left(\mathbb{M}_{t, t+1}^{*}\right)-\ln \left(\mathbb{M}_{t, t+1}\right)
$$

The solution to the international consumption allocation problem is given by:

$$
\begin{aligned}
Z_{t} \phi_{\mathrm{C}} \mathcal{Y}_{h, t}^{*} & =\left(1-\phi_{\mathrm{C}}\right) \mathcal{Y}_{h, t}, \\
Z_{t}\left(1-\phi_{\mathrm{C}}\right) \mathcal{Y}_{f, t}^{*} & =\phi_{\mathrm{C}} \mathcal{Y}_{f, t} .
\end{aligned}
$$

The stochastic discount factors expressed in units of the utility flow implied by above preferences using standard derivations can be expressed as:

$$
\begin{aligned}
& \mathbb{M}_{t, t+1}=\beta\left(\frac{u_{t+1}}{u_{t}}\right)^{-\frac{1}{\psi}}\left(\frac{U_{t+1}}{\mathbb{E}_{t}\left[\left(U_{t+1}\right)^{1-\gamma}\right]^{\frac{1}{1-\gamma}}}\right)^{\frac{1}{\psi}-\gamma} \\
& \mathbf{M}_{t, t+1}^{*}=\beta\left(\frac{u_{t+1}^{*}}{u_{t}^{*}}\right)^{-\frac{1}{\psi}}\left(\frac{U_{t+1}^{*}}{\mathbb{E}_{t}\left[\left(U_{t+1}^{*}\right)^{1-\gamma}\right]^{\frac{1}{1-\gamma}}}\right)^{\frac{1}{\psi}-\gamma} .
\end{aligned}
$$

The stochastic discount factors expressed in units of the respective final good are:

$$
\begin{aligned}
& \mathbb{M}_{t, t+1}^{l o c}=\mathbb{M}_{t, t+1} \frac{\partial u_{t+1} / \partial \mathcal{Y}_{h, t+1}}{\partial u_{t} / \partial \mathcal{Y}_{h, t}}=\mathbb{M}_{t, t+1}\left(\frac{u_{t+1}}{u_{t}}\right)^{\frac{1}{f}}\left(\frac{C_{t+1}}{C_{t}}\right)^{1-\frac{1}{f}}\left(\frac{\mathcal{Y}_{h, t+1}}{\mathcal{Y}_{h, t}}\right)^{-1} \\
& \mathbb{M}_{t, t+1}^{*, l o c}=\mathbb{M}_{t, t+1}^{*} \frac{\partial u_{t+1}^{*} / \partial \mathcal{Y}_{f, t+1}^{*}}{\partial u_{t}^{*} / \partial \mathcal{Y}_{f, t}^{*}}=\mathbb{M}_{t, t+1}^{*}\left(\frac{u_{t+1}^{*}}{u_{t}^{*}}\right)^{\frac{1}{f}}\left(\frac{C_{t+1}^{*}}{C_{t}^{*}}\right)^{1-\frac{1}{f}}\left(\frac{\mathcal{Y}_{f, t+1}^{*}}{\mathcal{Y}_{f, t}^{*}}\right)^{-1} .
\end{aligned}
$$

The households choose their labor supply as if wages can adjust without frictions. However and following Uhlig (2007), the total labor supply does not reach the market resulting in sticky wages. The wages, 
therefore, evolve as follows:

$$
W_{t}=\left(W_{t-1} Q_{t} / Q_{t-1}\right)^{\mu}\left(W_{u, t}\right)^{1-\mu}, \quad W_{t}^{*}=\left(W_{t-1}^{*} Q_{t}^{*} / Q_{t-1}^{*}\right)^{\mu}\left(W_{u, t}^{*}\right)^{1-\mu},
$$

where $\mu$ determines the severity of wage rigidities, and $W_{u, t}, W_{u, t}^{*}$ represent frictionless wages. In particular, $\mu=0$ implies the absence of wage rigidities. If the wage rate cannot adjust optimally, it is assumed that it is indexed to aggregate economic growth, determined by the growth rate of the number of intermediate goods $Q_{t}$ and $Q_{t}^{*}$, respectively. The dynamics of $Q_{t}$ and $Q_{t}^{*}$ are determined later in Section A.4. The optimal consumption-leisure trade-off conditions are given by:

$$
\begin{aligned}
& W_{u, t}=\frac{1-\tau}{\tau \phi_{\mathrm{C}}}\left(\frac{C_{t}}{\bar{L}-L_{t}}\right)^{\frac{1}{f}} \frac{\mathcal{Y}_{h, t}}{C_{t}}\left[\left(Q_{t}\right)^{\phi_{\mathrm{C}}}\left(Q_{t}^{*}\right)^{1-\phi_{\mathrm{C}}}\right]^{1-\frac{1}{f}} \\
& W_{u, t}^{*}=\frac{1-\tau}{\tau \phi_{\mathrm{C}}}\left(\frac{C_{t}^{*}}{\bar{L}-L_{t}^{*}}\right)^{\frac{1}{f}} \frac{\mathcal{Y}_{f, t}^{*}}{C_{t}^{*}}\left[\left(Q_{t}^{*}\right)^{\phi_{\mathrm{C}}}\left(Q_{t}\right)^{1-\phi_{\mathrm{C}}}\right]^{1-\frac{1}{f}}
\end{aligned}
$$

\section{A.2 Final goods sectors}

I closely follow Bena, Garlappi, and Grüning (2016) in modeling the final goods sector, the intermediate goods sector, and the R\&D technologies. There is a representative perfectly competitive firm in the final goods sector producing the respective final good using capital $K_{t}\left(K_{t}^{*}\right)$, labor $L_{t}\left(L_{t}^{*}\right)$, and a composite of local intermediate goods $G_{t}\left(G_{t}^{*}\right)$ with technology:

$$
Y_{t}=\left[\left(K_{t}\right)^{\alpha}\left(\Omega_{t} L_{t}\right)^{1-\alpha}\right]^{1-\xi}\left[G_{t}\right]^{\xi}, \quad Y_{t}^{*}=\left[\left(K_{t}^{*}\right)^{\alpha}\left(\Omega_{t}^{*} L_{t}^{*}\right)^{1-\alpha}\right]^{1-\xi}\left[G_{t}^{*}\right]^{\xi}
$$

where $\alpha \in(0,1)$ is the capital share, $\xi \in(0,1)$ is the share of intermediate goods, and $\Omega_{t}=e^{z_{t}+a_{t}}$ $\left(\Omega_{t}^{*}=e^{z_{t}+a_{t}^{*}}\right)$ is a productivity shock with two components. First, the common or world shock $z_{t}$ affects the productivity in both countries. It follows a strictly stationary $\operatorname{AR}(1)$ process:

$$
z_{t}=\rho_{z} z_{t-1}+e^{\varphi_{z, t-1}} \varepsilon_{z, t}, \varepsilon_{z, t} \sim \mathcal{N}\left(0, \sigma_{z}^{2}\right)
$$

Second, the two idiosyncratic shocks $a_{t}$ and $a_{t}^{*}$ are determined by similar processes:

$$
a_{t}=\rho_{a} a_{t-1}+e^{\varphi_{a, t-1}} \varepsilon_{a, t}, \quad a_{t}^{*}=\rho_{a} a_{t-1}^{*}+e^{\varphi_{a, t-1}^{*}} \varepsilon_{a, t}^{*}, \quad \varepsilon_{a, t}, \varepsilon_{a, t}^{*} \sim \mathcal{N}\left(0, \sigma_{a}^{2}\right) .
$$

These three productivity shocks are mutually independent. Moreover, all three productivity processes are subject to volatility shocks. These stochastic volatility shocks are induced by the following processes:

$$
\varphi_{z, t}=\rho_{\varphi} \varphi_{z, t-1}+\varepsilon_{\varphi, z, t}, \quad \varphi_{a, t}=\rho_{\varphi} \varphi_{a, t-1}+\varepsilon_{\varphi, a, t}, \quad \varphi_{a, t}^{*}=\rho_{\varphi} \varphi_{a, t-1}^{*}+\varepsilon_{\varphi, a, t}^{*},
$$

where $\rho_{\varphi}$ is the common persistence of all stochastic volatility processes and the random variables $\varepsilon_{\varphi, z, t}$, $\varepsilon_{\varphi, a, t}$, and $\varepsilon_{\varphi, a, t}^{*}$ are independently and identically normally distributed with mean zero and variance $\sigma_{\varphi}^{2}$. I assume that in each country the intermediate goods sector is composed of a continuum of firms with measure one indexed by $i \in[0,1](l \in[0,1])$. Each intermediate goods sector firm (incumbent) in each country produces a single intermediate good. The intermediate goods are aggregated according to:

$$
G_{t}=\left[\int_{0}^{1}\left(q_{i, t}\right)^{1-\frac{1}{\nu}}\left(x_{i, t}\right)^{\frac{1}{\nu}} d i\right]^{\nu}, \quad G_{t}^{*}=\left[\int_{0}^{1}\left(q_{l, t}^{*}\right)^{1-\frac{1}{\nu}}\left(x_{l, t}^{*}\right)^{\frac{1}{\nu}} d l\right]^{\nu},
$$


where $x_{i, t}\left(q_{i, t}\right)$ and $x_{l, t}^{*}\left(q_{l, t}^{*}\right)$ are the quantities (qualities) of intermediate good $i$ and $l$ produced in the home and foreign country, respectively, and $\nu /(\nu-1)$ is the elasticity of substitution between any two intermediate goods. The final goods sector only uses local goods and intermediate goods cannot be exported to or imported from the other country.

The final goods firms take the pricing kernel of the respective country's household in local units $\mathbb{M}_{0, t}^{l o c}$ and $\mathbb{M}_{0, t}^{*, l o c}$ as given and choose investment $I_{t}\left(I_{t}^{*}\right)$, labor $L_{t}\left(L_{t}^{*}\right)$, next period's capital $K_{t+1}\left(K_{t+1}^{*}\right)$, and the quantity of each intermediate good $i(l), x_{i, t}\left(x_{l, t}^{*}\right)$, to maximize their values:

$$
\max _{\left\{I_{t}, L_{t}, K_{t+1}, x_{i, t}\right\}_{i \in\left[0, N_{t}\right] ; t \geq 0}} \mathbb{E}_{0}\left[\sum_{t=0}^{\infty} \mathbb{M}_{0, t}^{l o c} D_{t}\right], \max _{\left\{I_{t}^{*}, L_{t}^{*}, K_{t+1}^{*}, x_{l, t}^{*}\right\}_{l \in\left[0, N_{t}^{*}\right] ; t \geq 0}} \mathbb{E}_{0}\left[\sum_{t=0}^{\infty} \mathbf{M}_{0, t}^{*, l o c} D_{t}^{*}\right],
$$

where dividends are given by:

$$
D_{t}=Y_{t}-I_{t}-W_{t} L_{t}-\int_{0}^{1} p_{i, t} x_{i, t} d i, \quad D_{t}^{*}=Y_{t}^{*}-I_{t}^{*}-W_{t}^{*} L_{t}^{*}-\int_{0}^{1} p_{l, t}^{*} x_{l, t}^{*} d l,
$$

and where the price of intermediate good $i(l)$ at time $t$ is denoted by $p_{i, t}\left(p_{l, t}^{*}\right)$. Capital accumulates according to:

$$
K_{t+1}=(1-\delta) K_{t}+\Lambda\left(\frac{I_{t}}{K_{t}}\right) K_{t}, \quad K_{t+1}^{*}=(1-\delta) K_{t}^{*}+\Lambda\left(\frac{I_{t}^{*}}{K_{t}^{*}}\right) K_{t}^{*},
$$

where the capital depreciation rate is given by $\delta$, and the convex capital adjustment cost function is specified as in Jermann (1998). The resulting equilibrium conditions for the home country are given by:

$$
\begin{aligned}
W_{t} L_{t} & =(1-\alpha)(1-\xi) Y_{t}, \\
1 & =\mathbb{E}_{t}\left[\mathbf{M}_{t, t+1}^{l o c} \Lambda_{t}^{\prime}\left(\frac{\alpha(1-\xi) Y_{t+1}-I_{t+1}}{K_{t+1}}+\frac{\Lambda_{t+1}+1-\delta}{\Lambda_{t+1}^{\prime}}\right)\right], \\
x_{i, t} & =\xi^{\frac{\nu}{\nu-1}}\left(K_{t}^{\alpha}\left(\Omega_{t} L_{t}\right)^{1-\alpha}\right)^{\frac{(1-\xi) \nu}{\nu-1}} G_{t}^{\frac{\xi \nu-1}{\nu-1}} p_{i, t}^{\frac{\nu}{1-\nu}} q_{i, t},
\end{aligned}
$$

The equilibrium conditions of the foreign country are straightforward to write down since they are equivalent to the ones above.

\section{A.3 Intermediate goods sectors and R\&D technologies}

There is a monopolistically competitive intermediate goods sector in each country, in which a continuum of incumbent firms produces intermediate goods for the respective final goods sector. Each incumbent can invest in R\&D to obtain an incremental innovation to increase profits from its monopoly. At the same time, entrants deploy R\&D giving them a chance to displace an incumbent by inventing a radically better product. If neither an incumbent nor an entrant innovates on a particular product line, it is assumed that this intermediate good's quality depreciates in order to capture patent obsolescence and decreasing monopoly profits over time.

\section{A.3.1 Incumbents}

At any point in time $t$, intermediate good $i(l)$ is produced by an incumbent firm which holds a fully enforced patent on the intermediate good. Incumbents need one unit of the final good to produce one 
unit of its respective intermediate good. Incumbent $i(l)$ in the home (foreign) country sets the price $p_{i, t}$ $\left(p_{l, t}^{*}\right)$ to maximize its profits:

$$
\pi_{i, t}=\max _{\left\{p_{i, t}\right\}}\left\{p_{i, t} x_{i, t}-x_{i, t}\right\}, \quad \pi_{l, t}^{*}=\max _{\left\{p_{l, t}^{*}\right\}}\left\{p_{l, t}^{*} x_{l, t}^{*}-x_{l, t}^{*}\right\},
$$

taking the demand schedule $x_{i, t}\left(x_{l, t}^{*}\right)$ for intermediate good $i(l)$ as determined by the final goods firm as given, i.e. Equation (A.28). The optimal prices are given by:

$$
p_{i, t} \equiv \nu, \quad p_{l, t}^{*} \equiv \nu
$$

This, in turn, implies that the demand of intermediate goods and the profits are identical across intermediate goods, i.e. $x_{i, t} \equiv x_{t}, x_{l, t}^{*} \equiv x_{t}^{*}, p_{i, t} \equiv \pi_{t}$, and $p_{l, t}^{*} \equiv \pi_{t}^{*}$.

At each date $t$, the incumbent firm can improve its product quality by investing in R\&D. To capture technology spillover, the incumbent firm uses both the home and the foreign country's final good in its innovation technology. If the home incumbent spends $s_{I, h, i, t} q_{i, t}$ units of the home country's and $s_{I, f, i, t} q_{i, t}$ of the foreign country's final good on R\&D to improve its intermediate good with quality $q_{i, t}$, the probability of a successful incremental product innovation by this incumbent is equal to $\Phi^{\mathrm{I}}\left(s_{I, i, t}\right)$, where:

$$
\Phi^{\mathrm{I}}\left(s_{I, i, t}\right)=\eta_{\mathrm{I}}\left(s_{I, i, t}\right)^{\omega_{\mathrm{I}}}, \quad s_{I, i, t}=\left(s_{I, h, i, t}\right)^{\phi_{\mathrm{I}}}\left(s_{I, f, i, t}\right)^{1-\phi_{\mathrm{I}}} .
$$

A successful incremental innovation by incumbents creates a patent to intermediate good $i$ with quality $\kappa_{\mathrm{I}} q_{i, t}$, where $\kappa_{\mathrm{I}}>1$. Hence, the quality produced (and profits) of the incumbent increases by a factor of $\kappa_{\mathrm{I}}-1$. The total amount of R\&D expenditure of home and foreign country's final good by incumbent firms in the home country is:

$$
S_{I, h, t}=\int_{0}^{1} s_{I, h, i, t} q_{i, t} d i, \quad S_{I, f, t}=\int_{0}^{1} s_{I, f, i, t} q_{i, t} d i .
$$

Similar expressions hold for the foreign incumbents. In particular, innovation probability, R\&D expenditure bundle, and aggregate $\mathrm{R} \& \mathrm{D}$ expenditures are given by:

$\Phi^{\mathrm{I}}\left(s_{I, f, l, t}^{*}\right)=\eta_{\mathrm{I}}\left(s_{I, f, l, t}^{*}\right)^{\omega_{\mathrm{I}}}, s_{I, f, l, t}^{*}=\left(s_{I, f, l, t}^{*}\right)^{\phi_{\mathrm{I}}}\left(s_{I, h, l, t}^{*}\right)^{1-\phi_{\mathrm{I}}}, S_{I, f, t}^{*}=\int_{0}^{1} s_{I, f, l, t}^{*} q_{l, t}^{*} d l, S_{I, h, t}^{*}=\int_{0}^{1} s_{I, h, l, t}^{*} q_{l, t}^{*} d l$.

Due to the equality of prices and quantities across all firms in the intermediate goods sector and concentrating on the linear balanced growth path equilibrium, the value of any incumbent in the respective country is also identical and equal to the patent value of producing any intermediate good of the respective country. The values of any incumbent in the home and foreign economy are given by:

$$
\begin{aligned}
& v_{t}=\max _{\left\{s_{I, h, t}, s_{I, f, t}\right\}}\left\{\pi_{t}-s_{I, h, t}-P_{t} s_{I, f, t}+\mathbb{E}_{t}\left[\mathrm{M}_{t, t+1}^{l o c} v_{t+1}\left(\Phi^{\mathrm{I}}\left(s_{I, t}\right) \kappa_{\mathrm{I}}+\left(1-\Phi^{\mathrm{I}}\left(s_{I, t}\right)-\hat{\Phi}^{\mathrm{E}}\left(s_{E, t}\right)\right)\left(1-\kappa_{\mathrm{D}}\right)\right)\right]\right\}, \\
& v_{t}^{*}=\max _{\left\{s_{I, f, t}^{*}, s_{I, h, t}^{*}\right\}}\left\{\pi_{t}^{*}-s_{I, f, t}^{*}-\frac{s_{I, h, t}^{*}}{P_{t}}+\mathbb{E}_{t}\left[\mathrm{M}_{t, t+1}^{*, l o c} v_{t+1}^{*}\left(\Phi^{\mathrm{I}}\left(s_{I, t}^{*}\right) \kappa_{\mathrm{I}}+\left(1-\Phi^{\mathrm{I}}\left(s_{I, t}^{*}\right)-\hat{\Phi}^{\mathrm{E}}\left(s_{E, t}^{*}\right)\right)\left(1-\kappa_{\mathrm{D}}\right)\right)\right]\right\},
\end{aligned}
$$

where $\kappa_{\mathrm{D}}$ is the probability that the quality of the intermediate good depreciates, i.e. it captures patent obsolescence, and where $\hat{\Phi}^{\mathrm{E}}\left(s_{E, t}\right)$ and $\hat{\Phi}^{\mathrm{E}}\left(s_{E, t}^{*}\right)$ are the innovation probabilities of entrants in the home and foreign country, as will be detailed in the next section. Due to the displacement effect, innovations 
by entrants have a negative effect on the incumbent value. The resulting equilibrium conditions are given by:

$$
\begin{aligned}
& 1=\left(\Phi^{\mathrm{I}}\right)^{\prime}\left(s_{I, t}\right) \phi_{\mathrm{I}} \frac{s_{I, t}}{s_{I, h, t}}\left(\kappa_{\mathrm{I}}-\kappa_{\mathrm{D}}\right) \mathbb{E}_{t}\left[\mathbb{M}_{t, t+1}^{l o c} v_{t+1}\right], \quad P_{t}=\left(\Phi^{\mathrm{I}}\right)^{\prime}\left(s_{I, t}\right)\left(1-\phi_{\mathrm{I}}\right) \frac{s_{I, t}}{s_{I, f, t}}\left(\kappa_{\mathrm{I}}-\kappa_{\mathrm{D}}\right) \mathbb{E}_{t}\left[\mathrm{M}_{t, t+1}^{l o c} v_{t+1}\right], \\
& 1=\left(\Phi^{\mathrm{I}}\right)^{\prime}\left(s_{I, t}^{*}\right) \phi_{\mathrm{I}} \frac{s_{I, t}^{*}}{s_{I, f, t}^{*}}\left(\kappa_{\mathrm{I}}-\kappa_{\mathrm{D}}\right) \mathbb{E}_{t}\left[\mathbb{M}_{t, t+1}^{*, l o c} v_{t+1}^{*}\right], \quad \frac{1}{P_{t}}=\left(\Phi^{\mathrm{I}}\right)^{\prime}\left(s_{I, t}^{*}\right) \phi_{\mathrm{I}} \frac{s_{I, t}^{*}}{s_{I, h, t}^{*}}\left(\kappa_{\mathrm{I}}-\kappa_{\mathrm{D}}\right) \mathbb{E}_{t}\left[\mathrm{M}_{t, t+1}^{*, l o c} v_{t+1}^{*}\right] .
\end{aligned}
$$

\section{A.3.2 Entrants}

There is an infinite supply of atomistic entrants in each country which deploy $R \& D$ in order to invent a new intermediate good. To capture technology spillovers, entrants in each country use both the home and the foreign country's final good in their innovation technologies. If all entrants in the home country together spend $s_{E, h, i, t} q_{i, t}$ units of the home country's final good and $s_{E, f, i, t} q_{i, t}$ units of the foreign country's final good on R\&D, the probability with which a home entrant makes a discovery is $\hat{\Phi}^{\mathrm{E}}\left(s_{E, i, t}\right):=s_{E, i, t} \Phi^{\mathrm{E}}\left(s_{E, i, t}\right)$, where:

$$
\Phi^{\mathrm{E}}\left(s_{E, i, t}\right)=\eta_{\mathrm{E}}\left(s_{E, i, t}\right)^{\omega_{\mathrm{E}}-1}, \quad s_{E, i, t}=\left(s_{E, h, i, t}\right)^{\phi_{\mathrm{E}}}\left(s_{E, f, i, t}\right)^{1-\phi_{\mathrm{E}}},
$$

where the functional form of $\Phi^{\mathrm{E}}(\cdot)$ is chosen as in Kung and Schmid (2015). The function $\Phi^{\mathrm{E}}\left(s_{E, i, t}\right)$ is taken as given by the atomistic entrants in the optimization problem (A.37). This captures a congestion externality and the fact that many entrants are likely to try out similar ideas in research. Thus, they are "fishing out of the same pond".

Equivalently, one obtains for the foreign country's entrants that if all entrants in the foreign country together spend $s_{E, f, l, t}^{*} q_{l, t}^{*}$ units of the foreign country's final good and $s_{E, h, l, t}^{*} q_{l, t}^{*}$ units of the home country's final good on $\mathrm{R} \& \mathrm{D}$, the probability with which a home entrant makes a discovery is $\hat{\Phi}^{\mathrm{E}}\left(s_{E, l, t}^{*}\right):=$ $s_{E, l, t}^{*} \Phi^{\mathrm{E}}\left(s_{E, l, t}^{*}\right)$, where:

$$
\Phi^{\mathrm{E}}\left(s_{E, l, t}^{*}\right)=\eta_{\mathrm{E}}\left(s_{E, l, t}^{*}\right)^{\omega_{\mathrm{E}}-1}, \quad s_{E, l, t}^{*}=\left(s_{E, f, l, t}^{*}\right)^{\phi_{\mathrm{E}}}\left(s_{E, h, l, t}^{*}\right)^{1-\phi_{\mathrm{E}}},
$$

where, again, the function $\Phi^{\mathrm{E}}(\cdot)$ is taken as given by the atomistic entrants in the optimization problem (A.38). Aggregate R\&D expenditures by entrants in both countries are given by:

$$
S_{E, h, t}=\int_{0}^{1} s_{E, h, i, t} q_{i, t} d i, S_{E, f, t}=\int_{0}^{1} s_{E, f, i, t} q_{i, t} d i, S_{E, f, t}^{*}=\int_{0}^{1} s_{E, f, l, t}^{*} q_{l, t}^{*} d l, S_{E, h, t}^{*}=\int_{0}^{1} s_{E, h, l, t}^{*} q_{l, t}^{*} d l .
$$

A successful radical innovation of an entrant creates a patent to intermediate good $i$ with quality $\kappa_{\mathrm{E}} q_{i, t}$ $\left(\kappa_{\mathrm{E}} q_{l, t}^{*}\right)$, where $\kappa_{\mathrm{E}}>\kappa_{\mathrm{I}}>1$. The respective incumbent cannot compete with this radically better product and has to exit the market.

Potential entrants in both countries enjoy free entry to the R\&D technology. Due to symmetry, the optimization problem for all entrants are identical. Thus, they maximize the net present value of future profits achieved if they become incumbents:

$$
\begin{gathered}
\max _{\left\{s_{E, h, t}, s_{E, f, t}\right\}}\left\{s_{E, t} \Phi^{\mathrm{E}}\left(s_{E, t}\right) \kappa_{\mathrm{E}} \mathbb{E}_{t}\left[\mathbb{M}_{t, t+1}^{l o c} v_{t+1}\right]-s_{E, h, t}-P_{t} s_{E, f, t}\right\}, \\
\max _{\left\{s_{E, f, t}^{*}, s_{E, h, t}^{*}\right\}}\left\{s_{E, t}^{*} \Phi^{\mathrm{E}}\left(s_{E, t}^{*}\right) \kappa_{\mathrm{E}} \mathbb{E}_{t}\left[\mathrm{M}_{t, t+1}^{*, l o c} v_{t+1}^{*}\right]-s_{E, f, t}^{*}-\frac{1}{P_{t}} s_{E, h, t}^{*}\right\} .
\end{gathered}
$$


The first-order conditions of these optimization problems are given by:

$$
\begin{array}{ll}
1=\Phi^{\mathrm{E}}\left(s_{E, t}\right) \phi_{\mathrm{E}} \frac{s_{E, t}}{s_{E, h, t}} \kappa_{\mathrm{E}} \mathbb{E}_{t}\left[\mathbb{M}_{t, t+1}^{l o c} v_{t+1}\right], & P_{t}=\Phi^{\mathrm{E}}\left(s_{E, t}\right)\left(1-\phi_{\mathrm{E}}\right) \frac{s_{E, t}}{s_{E, f, t}} \kappa_{\mathrm{E}} \mathbb{E}_{t}\left[\mathbb{M}_{t, t+1}^{l o c} v_{t+1}\right], \\
1=\Phi^{\mathrm{E}}\left(s_{E, t}^{*}\right) \phi_{\mathrm{E}} \frac{s_{E, t}^{*}}{s_{E, f, t}^{*}} \kappa_{\mathrm{E}} \mathbb{E}_{t}\left[\mathbb{M}_{t, t+1}^{*, l o c} v_{t+1}\right] & \frac{1}{P_{t}}=\Phi^{\mathrm{E}}\left(s_{E, t}^{*}\right)\left(1-\phi_{\mathrm{E}}\right) \frac{s_{E, t}^{*}}{s_{E, h, t}^{*}} \kappa_{\mathrm{E}} \mathbb{E}_{t}\left[\mathbb{M}_{t, t+1}^{*, l o c} v_{t+1}\right] .
\end{array}
$$

R\&D expenditures of potential entrants are thus chosen such that the marginal benefits of $R \& D$ are equal to the marginal costs.

\section{A.4 Technology capital and resource constraints}

The aggregate quality of intermediate goods or patents in each country represent the technology capital in the economy. Aggregate quality in the home and the foreign country is defined as follows:

$$
Q_{t}=\int_{0}^{1} q_{i, t} d i, \quad Q_{t}^{*}=\int_{0}^{1} q_{l, t}^{*} d l
$$

Sustained economic growth is achieved by growth in the quality of intermediate goods. The dynamics of aggregate technology capital growth are determined as follows:

$\frac{Q_{t+1}}{Q_{t}}=\kappa_{\mathrm{D}}+\left(\kappa_{\mathrm{I}}-\kappa_{\mathrm{D}}\right) \Phi^{\mathrm{I}}\left(s_{I, t}\right)+\left(\kappa_{\mathrm{E}}-\kappa_{\mathrm{D}}\right) \hat{\Phi}^{\mathrm{E}}\left(s_{E, t}\right), \quad \frac{Q_{t+1}^{*}}{Q_{t}^{*}}=\kappa_{\mathrm{D}}+\left(\kappa_{\mathrm{I}}-\kappa_{\mathrm{D}}\right) \Phi^{\mathrm{I}}\left(s_{I, t}^{*}\right)+\left(\kappa_{\mathrm{E}}-\kappa_{\mathrm{D}}\right) \hat{\Phi}^{\mathrm{E}}\left(s_{E, t}^{*}\right)$.

The growth rates thus depend exclusively on the level of R\&D expenditures by incumbents and entrants.

To close the model, resource constraints in both countries need to be specified. Net output of the home good $\mathcal{Y}_{t}$, which is available for both households' consumption, is final good output minus capital investment, final good input to production in the intermediate goods sector, and total R\&D expenditures. Similarly, this holds for the net output of the foreign good $\mathcal{Y}_{t}^{*}$. Hence, these net output quantities are pinned down by:

$\mathcal{Y}_{t}=Y_{t}-I_{t}-N_{t} X_{t}-S_{I, h, t}-S_{I, h, t}^{*}-S_{E, h, t}-S_{E, h, t}^{*}, \quad \mathcal{Y}_{t}^{*}=Y_{t}^{*}-I_{t}^{*}-N_{t}^{*} X_{t}^{*}-S_{I, f, t}^{*}-S_{I, f, t}-S_{E, f, t}^{*}-S_{E, f, t}$.

As each economy is growing, solving for the equilibrium requires normalizing of the growing real quantities by technology capital in order to make them stationary.

\section{A.5 Definition of equilibrium}

The decentralized equilibrium in this economy consists of (i) time paths of the net output available for consumption and the allocation of final goods for consumption $\left\{\mathcal{Y}_{t}, \mathcal{Y}_{f, t}, \mathcal{Y}_{h, t}, \mathcal{Y}_{t}^{*}, \mathcal{Y}_{f, t}^{*}, \mathcal{Y}_{h, t}^{*}\right\}_{t=0}^{t=\infty}$; (ii) time paths of consumption levels, utility bundles, final goods firm's dividends, physical capital, and investment $\left\{C_{t}, u_{t}, D_{t}, K_{t}, I_{t}, C_{t}^{*}, u_{t}^{*}, D_{t}^{*}, K_{t}^{*}, I_{t}^{*}\right\}_{t=0}^{t=\infty}$; (iii) time paths of technology capital growth $\left\{Q_{t+1} / Q_{t}, Q_{t+1}^{*} / Q_{t}^{*}\right\}_{t=0}^{t=\infty}$; (iv) time paths of R\&D expenditures $\left\{s_{I, t}, s_{E, t}, S_{I, h, t}, S_{I, f, t}, S_{E, h, t}, S_{E, h, t}^{*}, s_{I, t}^{*}\right.$, $\left.s_{E, t}^{*}, S_{I, f, t}^{*}, S_{I, h, t}^{*}, S_{E, f, t}^{*}, S_{E, f, t}\right\}_{t=0}^{t=\infty}$; (v) time paths of intermediate goods' prices, aggregate profits of incumbent, aggregate quantities of intermediate goods, and incumbent value functions $\left\{p_{t}, \Pi_{t}, X_{t}, v_{t}, p_{t}^{*}, \Pi_{t}^{*}\right.$, $\left.X_{t}^{*}, v_{t}^{*}\right\}_{t=0}^{t=\infty} ;$ (vi) time paths of wages, labor, and pricing kernels $\left\{W_{t}, L_{t}, M_{t, t+1}, M_{t, t+1}^{l o c}, W_{t}^{*}, L_{t}^{*}, M_{t, t+1}^{*}\right.$, $\left.M_{t, t+1}^{*, l o c}\right\}_{t=0}^{t=\infty}$; and (vii) time paths of the international consumption allocation factor and the terms of trade 
$\left\{Z_{t}, P_{t}\right\}_{t=0}^{t=\infty}$, such that (a) the representative households maximize lifetime utilities (A.1) and (A.2) subject to the definitions of the consumption and utility bundles (A.5), (A.3), and (A.3), as well as their budget constraints (A.7) and (A.8) by optimally choosing the allocation of final goods via trading in Arrow-Debreu securities and by optimally choosing their labor supply (Equations (A.10), (A.11), (A.12), (A.16), and (A.17)); (b) the final goods firm maximizes the present value of future dividends (A.23) by choosing labor, capital investment, next period's capital, and the demand for intermediate goods (Equations (A.26), (A.27), and (A.28)) subject to the definition of its dividends (A.24) and the Equation (A.25) for capital accumulation; (c) incumbents and potential entrants maximize present values of their future net profits stated in Equations (A.29), (A.32), (A.33), (A.37), and (A.38) by choosing the monopoly price and R\&D expenditures, respectively (Equations (A.30), (A.34), (A.35), (A.39), and (A.40)); (d) the wages follow dynamics given in Equation (A.15); (e) the pricing kernels are determined by Equations (A.13) and (A.14); (f) the terms of trade obey (A.9); and (g) the final goods markets clear (Equations (A.6) and (A.43)), given the vector of endogenous state variables $\left\{Q_{t}, Q_{t}^{*}\right\}$, whose dynamics are determined by Equation (A.42), and the vector of exogenous state variables $\left\{z_{t}, a_{t}, a_{t}^{*}, \varphi_{z, t}, \varphi_{a, t}, \varphi_{a, t}^{*}\right\}$, whose processes are stated in Equations (A.19), (A.20), and (A.21).

\section{A.6 Asset prices}

Using the stochastic discount factors, every payoff stream can be priced. I will price a claim on the aggregate dividend, which is defined by the sum of the profits of the final goods and intermediate goods sector in each country. Therefore, the aggregate stock market value in the home country is given by:

$$
D_{a, t}=D_{t}+\Pi_{t}-S_{I, h, t}-P_{t} S_{I, f, t}, \quad V_{a, t}=D_{a, t}+\mathbb{E}_{t}\left[\mathbb{M}_{t, t+1}^{l o c} V_{a, t+1}\right] .
$$

Alternatively, I also define the aggregate dividend as the net payout of the final goods sector, the intermediate goods sector, and the innovation sector, giving rise to the following definition of the aggregate stock market value:

$$
\widetilde{D}_{a, t}=D_{t}+\Pi_{t}-S_{I, h, t}-P_{t} S_{I, f, t}-S_{E, h, t}-P_{t} S_{E, f, t}, \quad \widetilde{V}_{a, t}=\widetilde{D}_{a, t}+\mathbb{E}_{t}\left[\mathbb{M}_{t, t+1}^{l o c} \widetilde{V}_{a, t+1}\right] .
$$

The intuitive reason behind the difference in these two definitions has to do with the fact whether one considers R\&D expenditures as supplied by the households (inventors are not employed by the existing firms) or as supplied by the productive firms in the economy (inventors are employed by the existing firms). The first definition is consistent with the first intuitive notion, whereas the second definition is consistent with the second intuitive notion.

Therefore, log returns of the aggregate stock market in the aforementioned two variants, and the risk-free rate, implied by a bond that pays one unit of the domestic final good the next period, are defined by:

$$
r_{a, t+1}=\log \left(\frac{V_{a, t+1}}{V_{a, t}-D_{a, t}}\right), \quad \widetilde{r}_{a, t+1}=\log \left(\frac{\widetilde{V}_{a, t+1}}{\widetilde{V}_{a, t}-\widetilde{D}_{a, t}}\right), \quad r_{f, t}=-\log \left(\mathbb{E}_{t}\left[\mathbb{M}_{t, t+1}^{l o c}\right]\right) .
$$

Similar definitions hold for the foreign country. In particular:

$$
\begin{array}{ll}
D_{a, t}^{*}=D_{t}^{*}+\Pi_{t}^{*}-S_{I, f, t}^{*}-\frac{S_{I, f, t}}{P_{t}}, & V_{a, t}^{*}=D_{a, t}^{*}+\mathbb{E}_{t}\left[\mathbb{M}_{t, t+1}^{*, l o c} V_{a, t+1}^{*}\right], \\
\widetilde{D}_{a, t}^{*}=D_{t}^{*}+\Pi_{t}^{*}-S_{I, f, t}^{*}-\frac{S_{I, h, t}^{*}}{P_{t}}-S_{E, f, t}^{*}-\frac{S_{E, h, t}^{*}}{P_{t}}, & \widetilde{V}_{a, t}^{*}=\widetilde{D}_{a, t}^{*}+\mathbb{E}_{t}\left[\mathbb{M}_{t, t+1}^{*, l o c} \widetilde{V}_{a, t+1}^{*}\right],
\end{array}
$$




$$
r_{a, t+1}^{*}=\log \left(\frac{V_{a, t+1}^{*}}{V_{a, t}^{*}-D_{a, t}^{*}}\right), \quad \widetilde{r}_{a, t+1}^{*}=\log \left(\frac{\widetilde{V}_{a, t+1}^{*}}{\widetilde{V}_{a, t}^{*}-\widetilde{D}_{a, t}^{*}}\right), \quad r_{f, t}^{*}=-\log \left(\mathbb{E}_{t}\left[\mathbb{M}_{t, t+1}^{*, l o c}\right]\right) .
$$

Finally, I also need the risk-free rates implied by a one-period bond that pays one unit of the consumption bundle $C_{t}=\left(\mathcal{Y}_{h, t}\right)^{\phi_{\mathrm{C}}}\left(\mathcal{Y}_{f, t}\right)^{1-\phi_{\mathrm{C}}}$ and $C_{t}^{*}=\left(\mathcal{Y}_{f, t}^{*}\right)^{\phi_{\mathrm{C}}}\left(\mathcal{Y}_{h, t}^{*}\right)^{1-\phi_{\mathrm{C}}}$ in the home country and in the foreign country, respectively, for the uncovered interest rate parity regressions. Hence, I let:

$$
r_{f, t}^{\text {bundle }}=-\log \left(\mathbb{E}_{t}\left[\mathbb{M}_{t, t+1}\right]\right), \quad r_{f, t}^{* \text {,bundle }}=-\log \left(\mathbb{E}_{t}\left[\mathbb{M}_{t, t+1}^{*}\right]\right) .
$$

\section{B Impulse Response Functions}

This appendix contains the impulse response functions of major macroeconomic quantities and asset prices of the home country in response to a home productivity shock and a foreign productivity shock, respectively, for all four calibrations reported in Table 1. I depict them here for completeness, as the discussion in the main text is centered around the simulated moments. However, to understand the origins of the effects of homogeneous and heterogeneous technology spillovers it is instructive to have a look at the impulse response functions as well. Specifically, Figure 1 depicts the impulse response functions of the incumbents' innovation probability, the amount of home goods used in the home incumbents' R\&D expenditure bundle, and the amount of foreign goods used in the home incumbents' R\&D expenditure bundle. Similarly, Figure 2 depicts those quantities for home entrants instead of home incumbents. Next, Figure 3 depicts the impulse response functions of the pricing kernel, the terms of trade, and the international consumption allocation factor. The impulse response functions of exchange rate growth and expected consumption growth are depicted in Figure 4. Figure 5 contains the impulse response functions of the home consumption bundle, the amount of home goods used in the home consumption bundle, and the amount of foreign goods used in the home consumption bundle. Finally, Figure 6 depicts the impulse response functions of labor, capital investment, and wages.

The following brief discussion sheds light on how heterogeneous technology spillovers affect the international transmission of shocks and thus why calibration [3] can match the correlation between incumbents' and entrants' innovation probabilities observed in the data. Figures 1 and 2 are the key to understanding this. A lower home bias in the $R \& D$ bundle of an innovating firm (incumbents or entrants), i.e. a higher internationalization of R\&D efforts, leads to home and foreign productivity shocks affecting the innovation probability of this innovating firm more similarly. In the case of the absence of technology spillovers or in the case of homogeneous technology spillovers, both home and foreign productivity shocks have exactly the same effect on the innovation probabilities of both incumbents and entrants. However, in calibration [3] incumbents' innovation probability reacts less positively to home productivity shocks and more positively to foreign productivity shocks. The opposite is observed for entrants, where foreign productivity shocks now even negatively affect the innovation probability. This breaks the perfect correlation between incumbents' and entrants' innovation probabilities and is also behind the other observed effects. In calibration [4], we observe the opposite direction of effects. Hence, we also observed the opposite effects in the moments. The negative correlation between incumbents' and entrants' innovation probabilities is a consequence of incumbents' innovation probability now decreasing in response to foreign productivity shocks, which leads to the observed negative correlation since entrants' innovation probability responds strongly positively to foreign productivity shocks.

Net exports become more counter-cyclical when incumbents' R\&D expenditures are more internationalized than entrants' R\&D expenditures, but even slightly pro-cyclical when entrants $R \& D$ expenditures 
are more internationalized than incumbents' $R \& D$ expenditures. An inspection of the impulse response functions, depicted in Figures 1 and 2, reveals why. Looking at the impulse reponse function for the quantity $s_{I, f, t}$, the import of the foreign good for home incumbents' R\&D expenditures increases a lot in response to a foreign productivity shock when the home bias parameter in the incumbents' bundle is low, as in calibration [3]. However, the positive impact is much smaller when the home bias parameter is relatively high, as in calibration [4]. The difference in the responses for the import of the foreign good for entrants' $R \& D$ is not as pronounced as for incumbents' $R \& D$. Since the effect of shocks to incumbents' $R \& D$ expenditures on economic growth are also bigger due to the absence of the creative destruction effect, the increased (decreased) counter-cyclicality of incumbents' R\&D expenditures mainly drives the increase (decrease) in the correlation between the net exports to output ratio and output in calibration [3] ([4]).

The intuition behind the differences in the correlation between exchange rate growth and consumption growth differentials can be extracted from an inspection of Figures 4 and 5 . Using the impulse response function for the normalized consumption bundle $C_{t} /\left[Q_{t}^{\phi_{\mathrm{C}}}\left(Q_{t}^{*}\right)^{1-\phi_{\mathrm{C}}}\right]$ reveals that the consumption growth differential reacts most positively in calibration [1], since the home consumption bundle reacts highly positively to home productivity shocks and slightly negatively to foreign productivity shocks. At the same time, exchange rate growth decreases in response to home productivity shocks and increases in response to foreign productivity shocks. Hence, country-specific productivity shocks induce a negative correlation between exchange rate growth and consumption growth differentials. Together with the common productivity shocks, one obtains a Backus and Smith (1993) correlation of only 0.10. The response of the consumption growth differential is similar in calibration [3], but exchange rate growth behaves oppositely to the behavior in calibration [1]. Hence, country-specific productivity shock induces a positive Backus and Smith (1993) correlation. Together with the common productivity shocks, the correlation reaches 0.96 in calibration [3]. The response of exchange rate growth in calibration [2] is similar to the one in calibration [3], but the consumption growth differential reacts less positively in calibration [2] than in calibration [3]. This explain why one sees a slightly lower Backus and Smith (1993) correlation in calibration [2], relative to calibration [3]. The Backus and Smith (1993) correlation is much lower in calibration [4], namely only 0.29 . The response of the consumption growth differential is comparable to the response in calibration [3], but exchange rate growth increases (decreases) significantly less in response to home (foreign) productivity shocks, explaining this relatively low correlation in calibration [4]. 


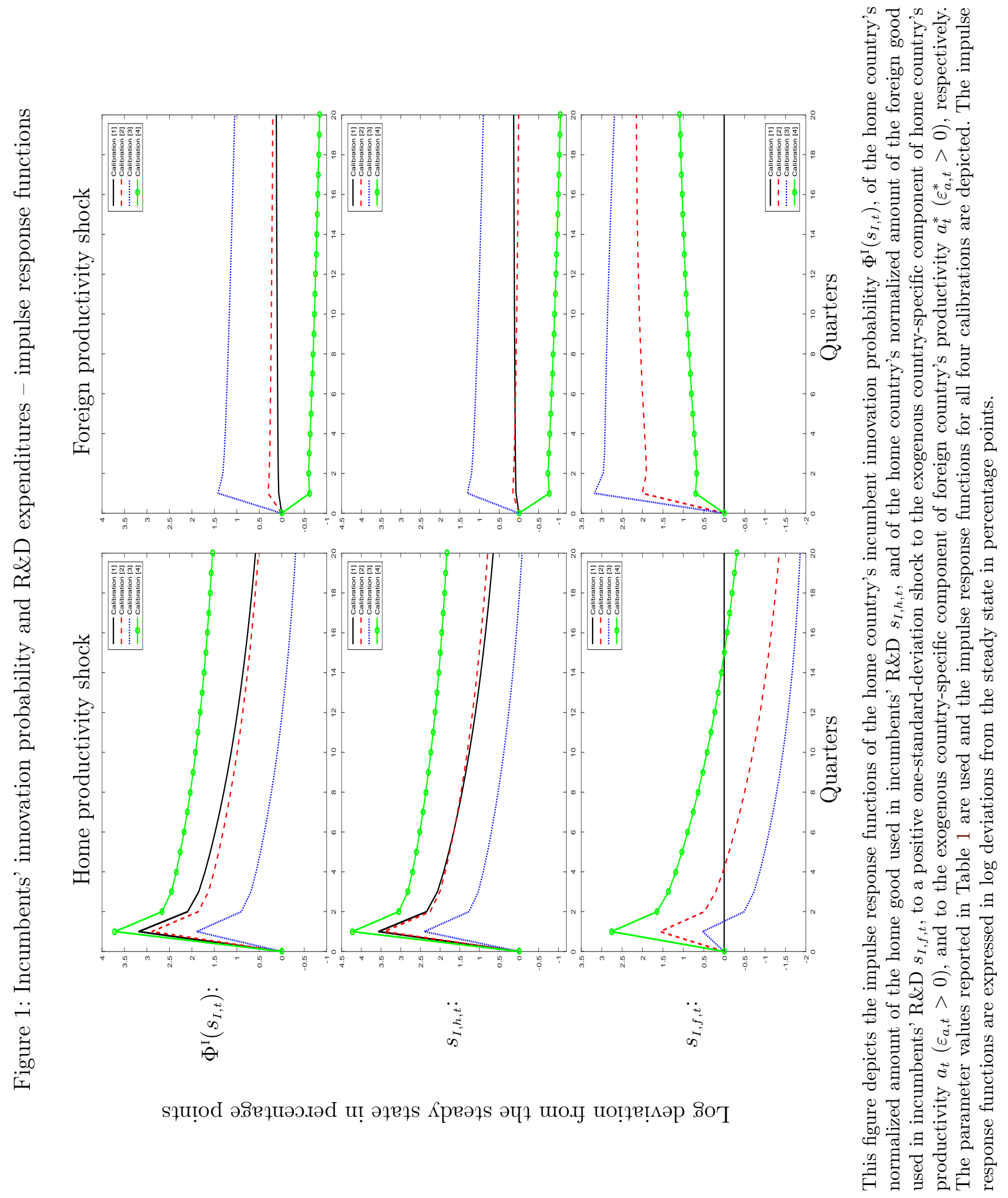




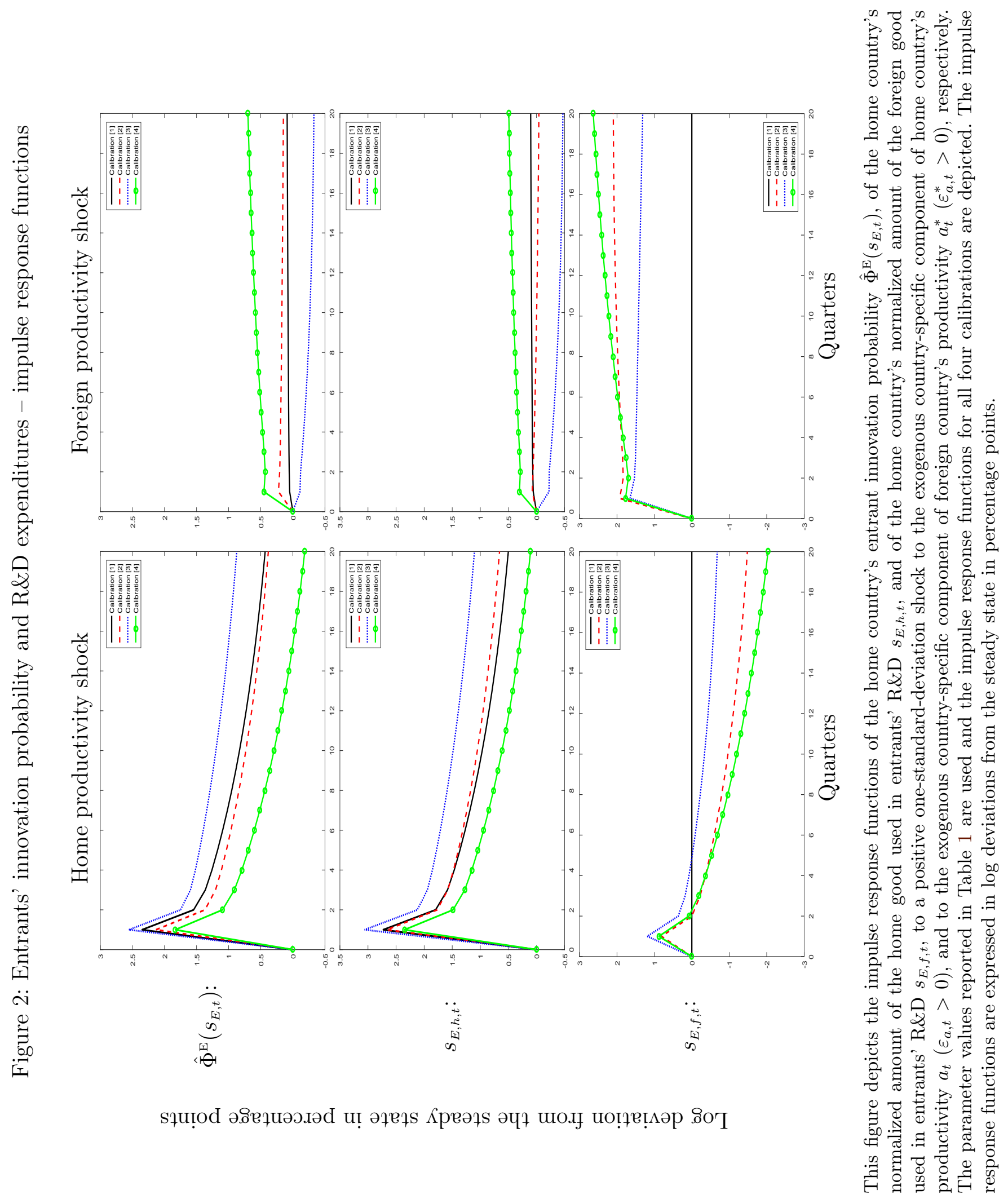




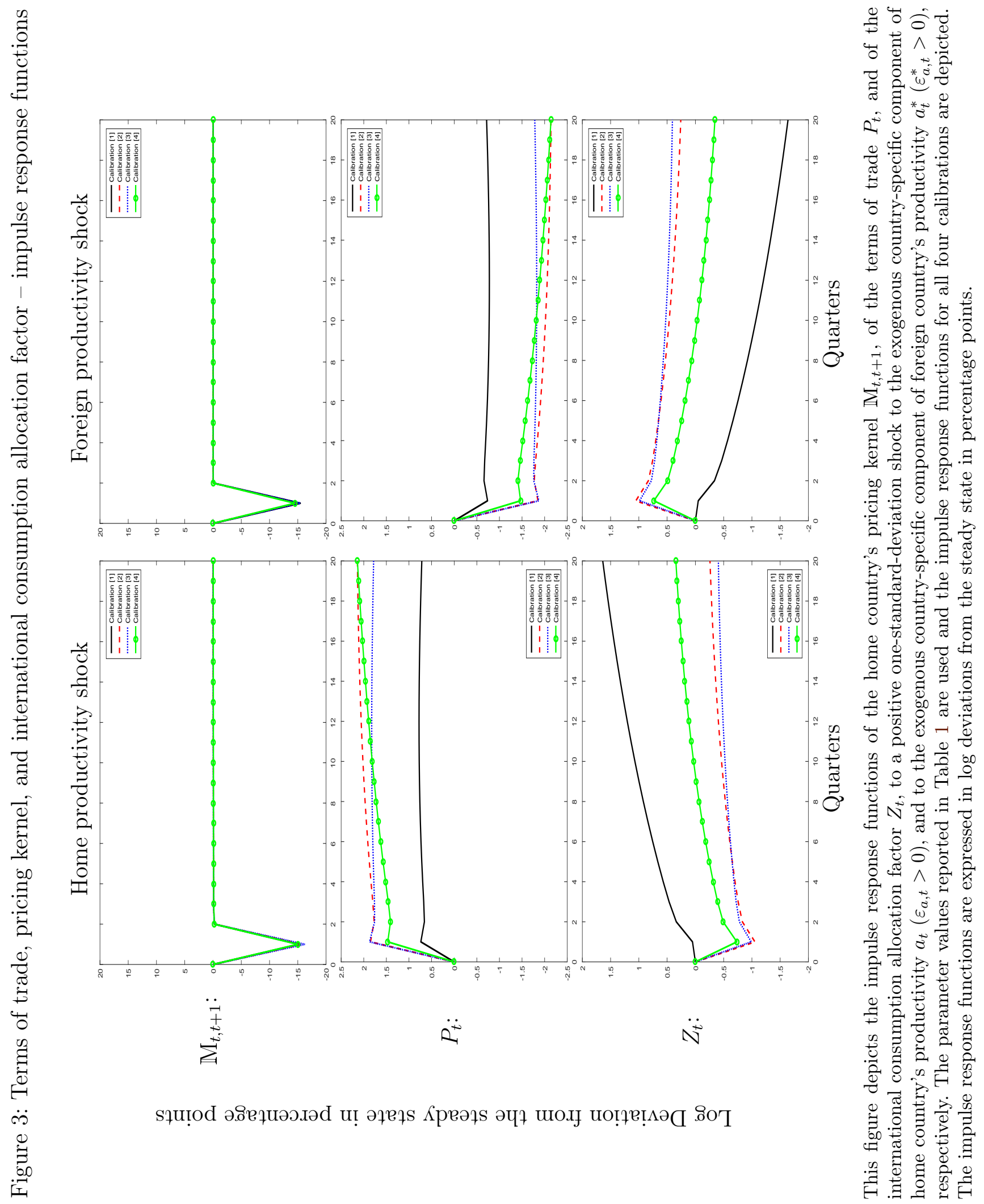




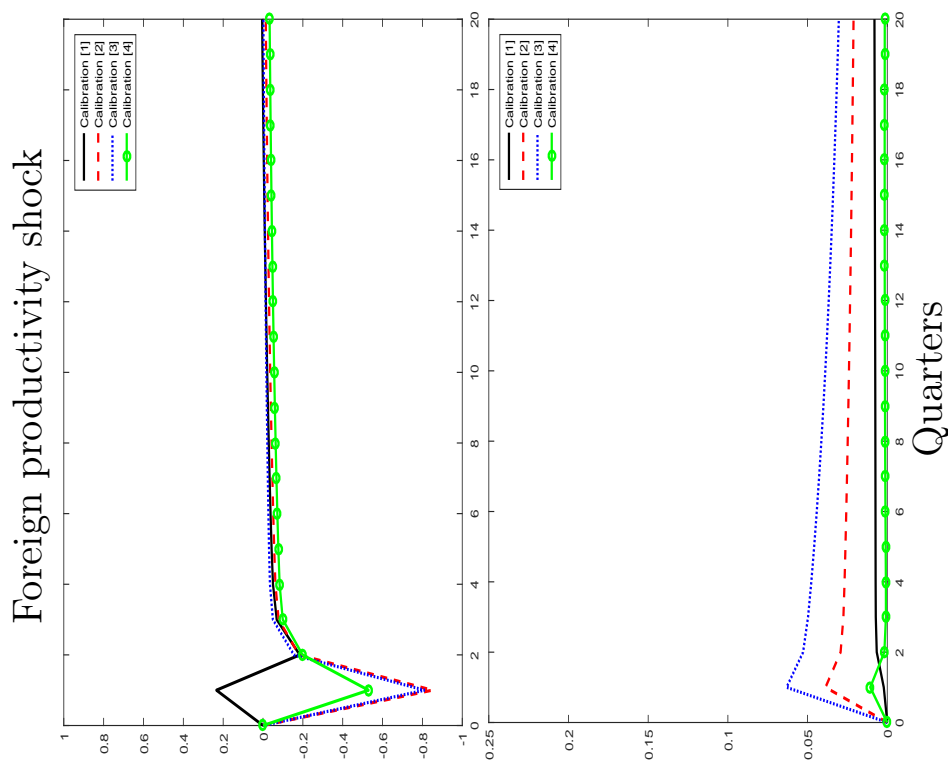

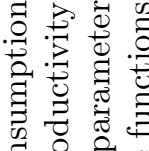

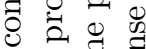
so ${ }^{\mathrm{m}} \mathrm{F}$ 的氙究

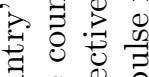
ఫ 0. है

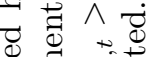
造

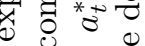
品焉

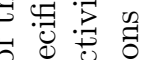
$\circ$ 要

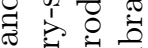

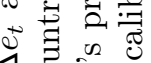
$\checkmark$ 。

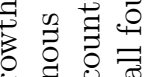

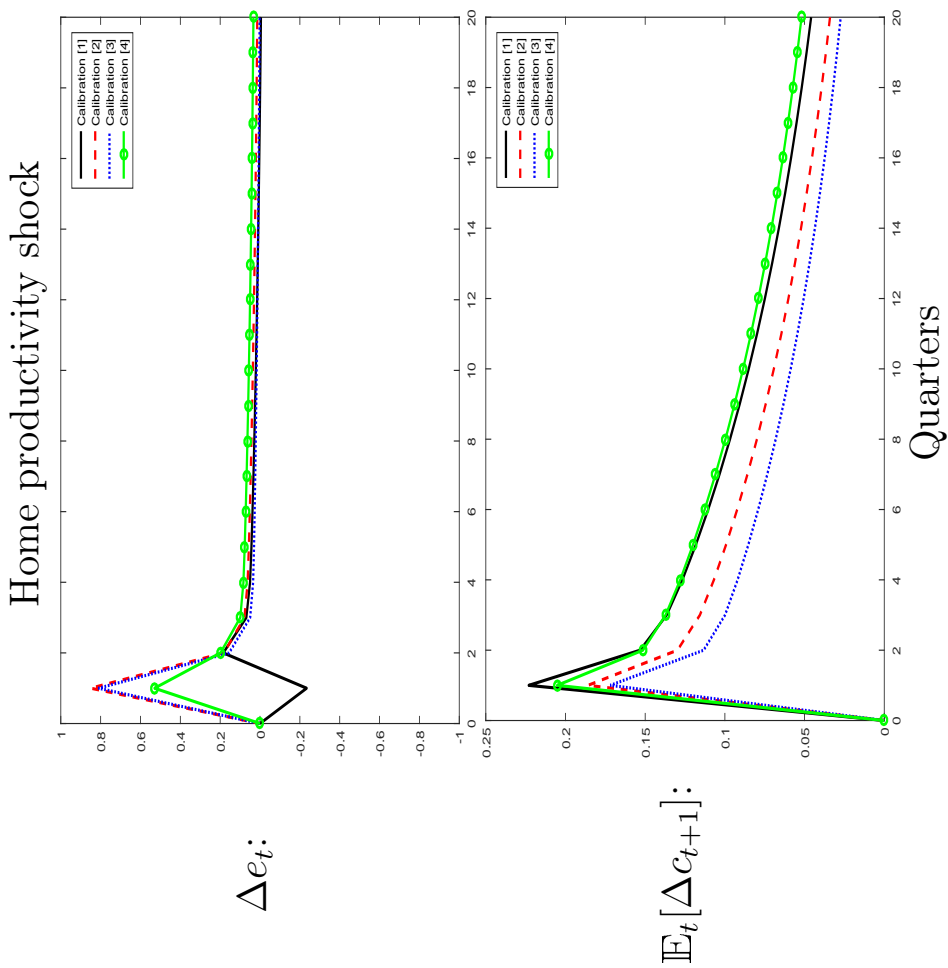

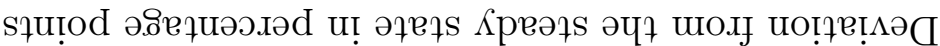
500000

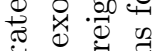
$\rightarrow$ 进. 敢 论 卷

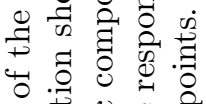

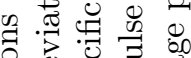

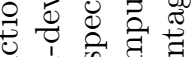

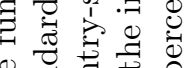

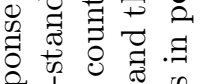

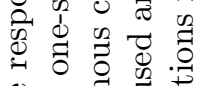

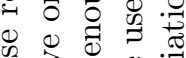

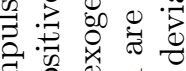
$\exists \circ \stackrel{0}{0}$

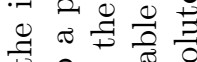

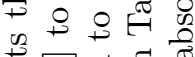
. 过苍范要

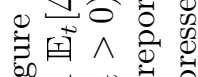

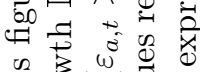

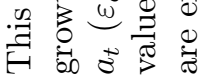




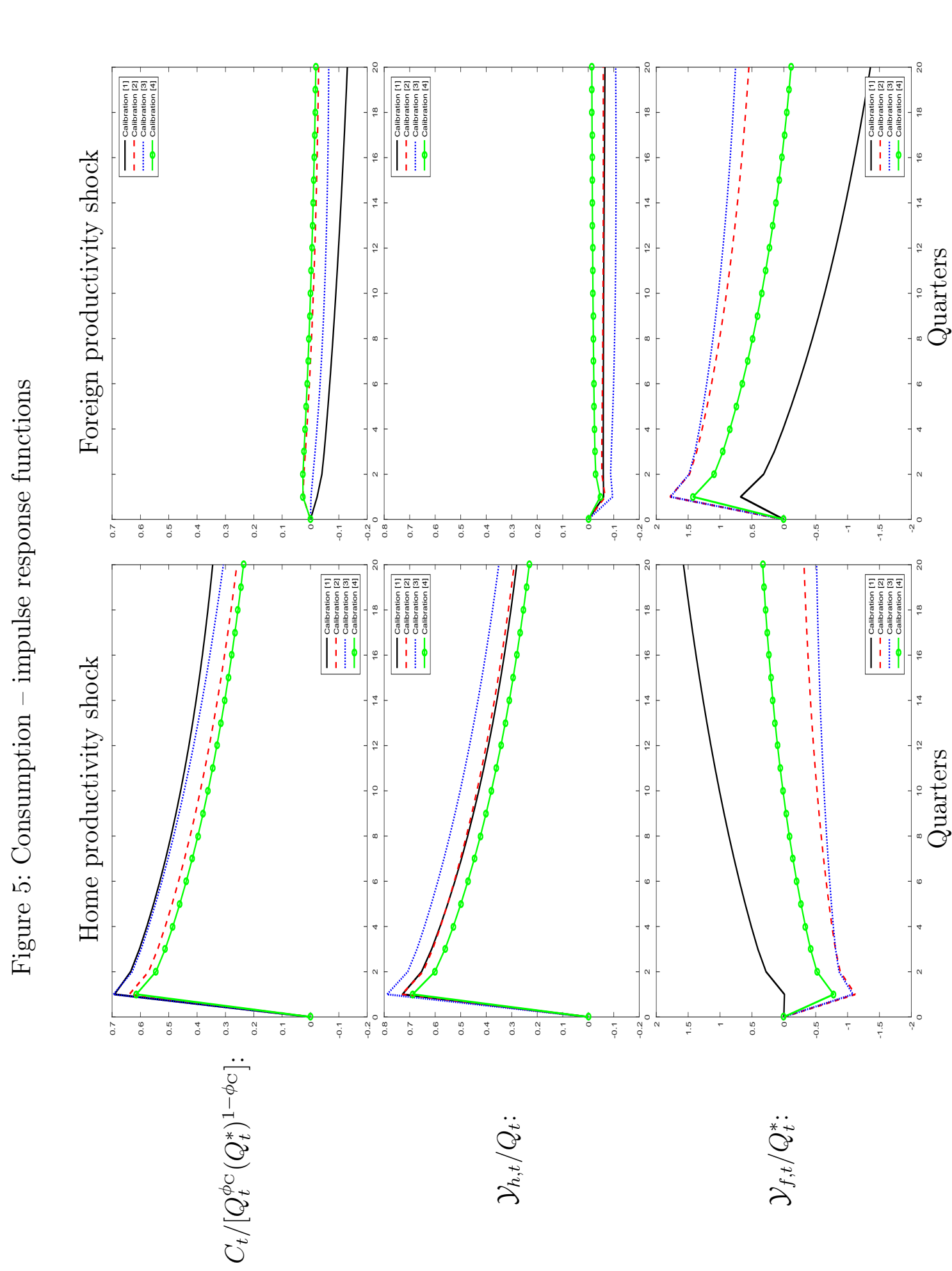

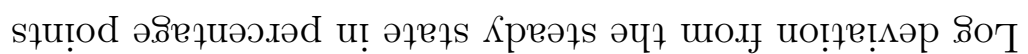

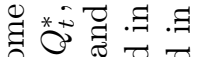

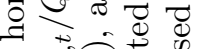

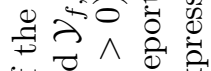

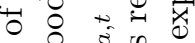

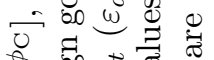
1.000 ف․

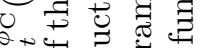

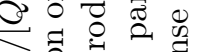

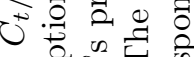

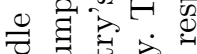
哥言要患

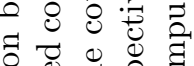

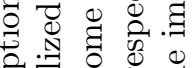
연 ज㲅

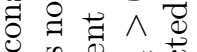

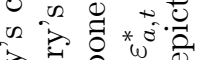

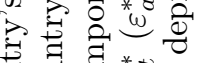
苛 0 욜

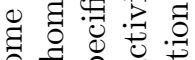
일

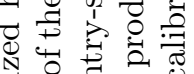

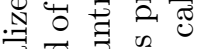
สี

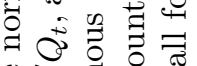
ॠ 虫 ป : 0.040

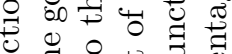

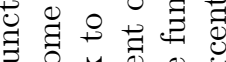
王

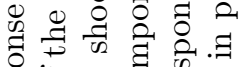
家苑

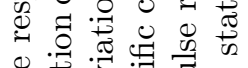

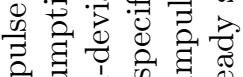

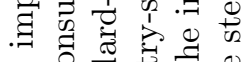
\% ज. : चี क्ष

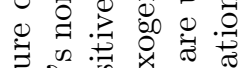
$\rightarrow 0$

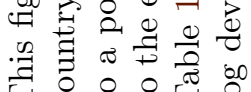




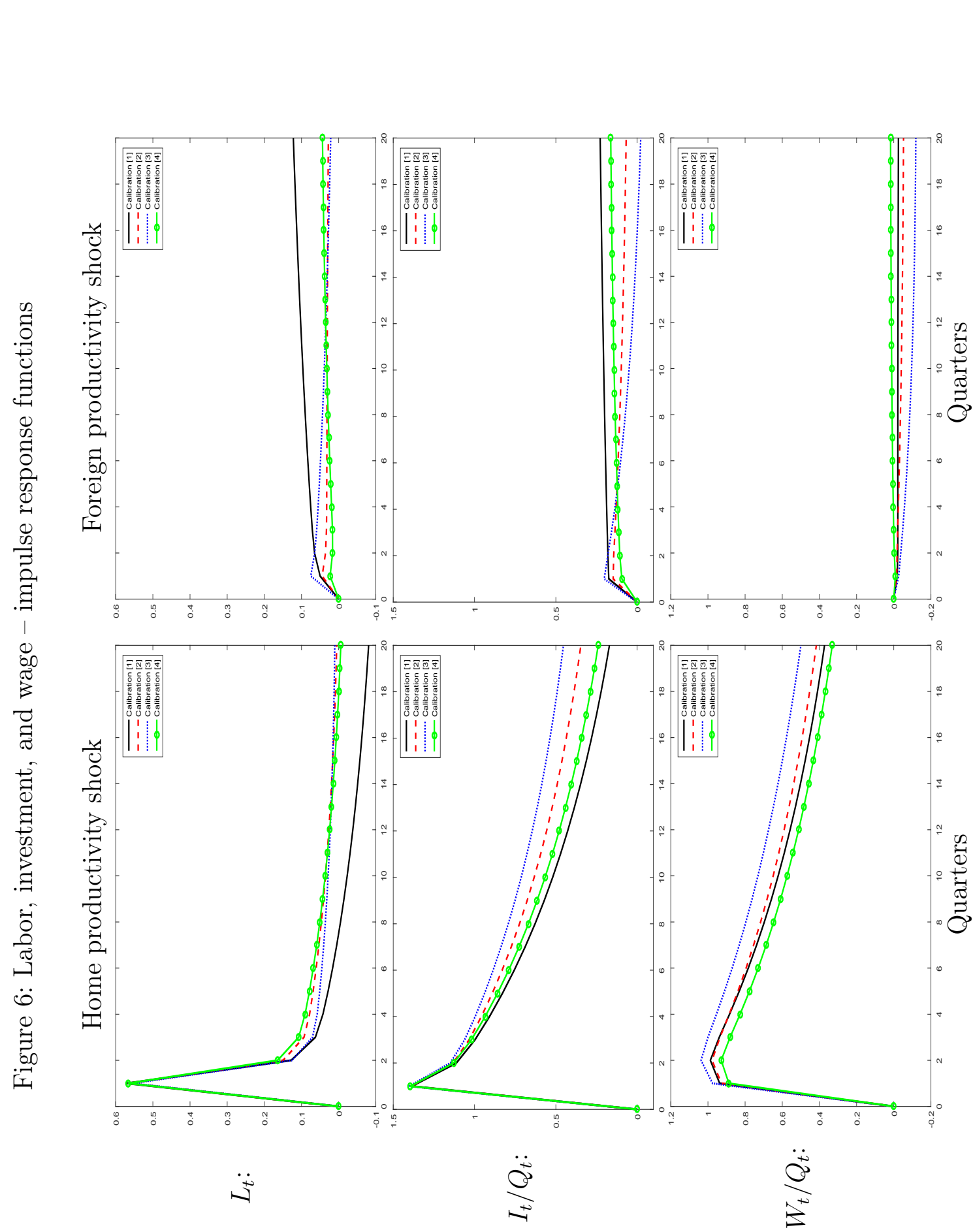

苞记总

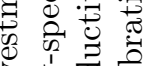

实

㺃

ฮै

赵 000.0

我.

苛 \&

常出寻

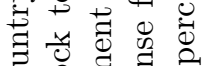

영 웅

进 专 考

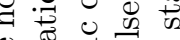

동

प्रे क्ञ

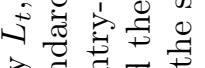

党贾

के

芒

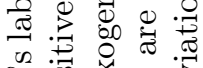

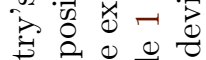

馬

요면

‡

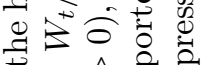

पै

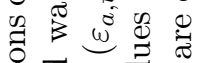

苾范

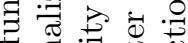

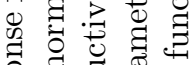

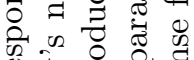

0

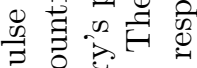

夏记节密

灵

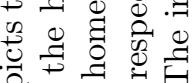

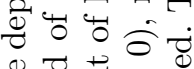

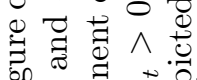

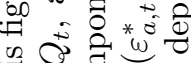

可造 


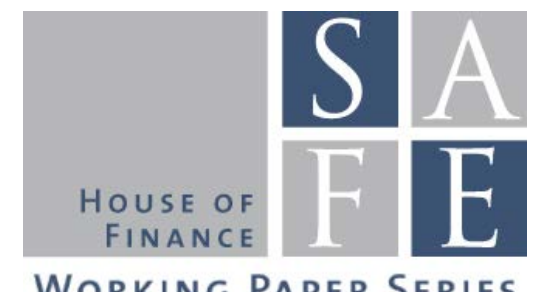

WORKING PAPER SERIES

\section{Recent Issues}

No. 184 Tobias Tröger

No. 183 Joost Driessen, Theo E. Nijman, Zorka Simon

No. 182 Mario Bellia, Loriana Pelizzon, Marti G. Subrahmanyam, Jun Uno, Darya Yuferova

No. 181 Holger Kraft, Farina Weiss

No. 180 Tobias H. Tröger

No. 179 Tobias H. Tröger

No. 178 Matthias Goldmann

No. 177 Michael Donadelli, Marcus Jüppner, Max Riedel, Christian Schlag

No. 176 Giuliano Curatola, Ilya Dergunov

No. 175 Reint Gropp, Deyan Radev

No. 174 Reint Gropp, Deyan Radev

No. 173 Merlin Kuate Kamga, Christian Wilde

No. 172 Ahmed Khalifa, Massimiliano Caporin, Michele Costola, Shawkat Hammoudeh
Remarks on the German Regulation of Crowdfunding

The Missing Piece of the Puzzle: Liquidity Premiums in Inflation-Indexed Markets

Coming Early to the Party

Consumption-Portfolio Choice with Preferences for Cash

Why MREL Won't Help Much

Too Complex to Work: A Critical Assessment of the Bail-in Tool under the European Bank Recovery and Resolution Regime

United in Diversity? The Relationship between Monetary Policy and Banking Supervision in the Banking Union

Temperature Shocks and Welfare Costs

International Capital Markets with TimeVarying Preferences

International Banking Conglomerates and the Transmission of Lending Shocks across Borders

Social Centralization, Bank Integration and the Transmission of Lending Shocks

Liquidity Premia in CDS Markets

Systemic Risk for Financial Institutions of Major Petroleum-based Economies: The Role of Oil 